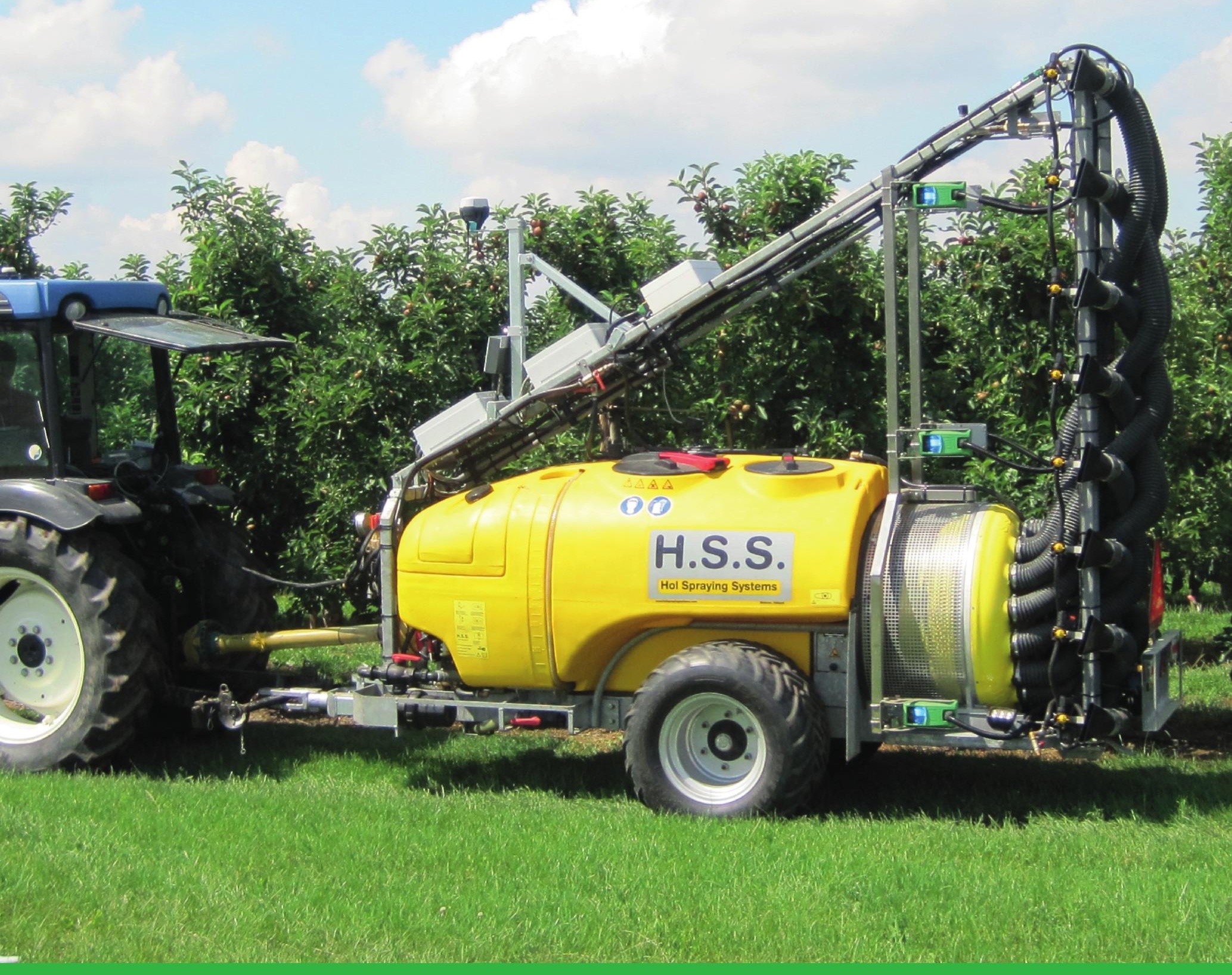

\title{
Driftmetingen H.S.S.-CF dwarsstroom boomgaardspuit met Intelligent Spray Application (I.S.A.) systeem
}





\section{Driftmetingen H.S.S.-CF dwarsstroom boomgaardspuit met Intelligent Spray Application (I.S.A.) systeem}

H. Stallinga, M. Snoussi, D.C. de Hoog, J.M.G.P. Michielsen, P. van Dalfsen, M. Wenneker \& J.C. van de Zande

Dit onderzoek is in opdracht van Hol Spraying Systems (H.S.S., Geldermalsen) uitgevoerd door Wageningen Plant Research, in het kader van onderzoek naar de driftreductie van de H.S.S. CF boomgaardspuit (projectnummer 3710472500).

WR is een onderdeel van Wageningen University \& Research, samenwerkingsverband tussen Wageningen University en de Stichting Wageningen Research.

Wageningen, december 2020

Rapport WPR-1025 
Stallinga, H., M. Snoussi, D.C. de Hoog, J.M.G.P. Michielsen, P. van Dalfsen, M. Wenneker \& J.C. van de Zande, 2020. Driftmetingen H.S.S.-CF dwarsstroom boomgaardspuit met Intelligent Spray Application (I.S.A.) systeem. Wageningen Research, Rapport WPR-1025. 38 blz.; 10 fig.; 10 tab.; 30 ref.

Dit rapport is gratis te downloaden op https://doi.org/10.18174/556122

Results of spray drift experiments are reported of the H.S.S. CF Intelligent Spray Application (I.S.A.) precision orchard crossflow fan sprayer. The H.S.S. CF I.S.A. is a precision cross-flow fan orchard sprayer equipped with sensors for green leaf detection and Pulse Width Modulation (PWM) modules at the nozzle-bodies for precise and variable dosing. The H.S.S. CF I.S.A. precision cross-flow fan orchard sprayer equipped with PWM operating nozzles, Lechler IDK 90-015 C flat fan venturi nozzles (75\% drift reduction), low air setting (1400 rpm fan) and green leaf detection sensors and singlesided spraying of the outside tree row obtains a spray drift reduction of $99.0 \%$ at $41 / 2-51 / 2 \mathrm{~m}$ distance from the last tree row compared to the reference spray system for fruit crop spraying in the Netherlands.

Measurement of airborne spray drift averaged over 0-10 m height at $7.5 \mathrm{~m}$ distance from the last tree row resulted in a spray drift reduction of $97.6 \%$ when spraying with the H.S.S. CF I.S.A. precision orchard sprayer.

Key words: precision orchard sprayer, spray drift, PWM, nozzle type, air assistance, green detection sensor, spray drift reduction, variable rate application

(C) 2020 Wageningen, Stichting Wageningen Research, Wageningen Plant Research, Postbus 16, 6700 AA Wageningen; T 03174807 00; www.wur.nl/plant-research

KvK: 09098104 te Arnhem

VAT NL no. 8113.83.696.B07

Stichting Wageningen Research. Alle rechten voorbehouden. Niets uit deze uitgave mag worden verveelvoudigd, opgeslagen in een geautomatiseerd gegevensbestand, of openbaar gemaakt, in enige vorm of op enige wijze, hetzij elektronisch, mechanisch, door fotokopieën, opnamen of enige andere manier zonder voorafgaande schriftelijke toestemming van Stichting Wageningen Research.

Stichting Wageningen Research is niet aansprakelijk voor eventuele schadelijke gevolgen die kunnen ontstaan bij gebruik van gegevens uit deze uitgave.

Rapport WPR-1025

Foto omslag: Jan van de Zande (HSS-CF-ISA-PrecisionOrchardSprayer_IMG_8242.JPG) 


\section{Inhoud}

Woord vooraf $\quad 5$

$\begin{array}{ll}\text { Samenvatting } & 7\end{array}$

$\begin{array}{ll}\text { Summary } & 9\end{array}$

$\begin{array}{lr}1 & 11\end{array}$

$2 \quad$ Materiaal en Methode $\quad 13$

2.1 Afstelling en beschrijving spuittechniek 13

2.1.1 Karakteristieken Munckhof standaard boomgaardspuit 13

2.1.2 Karakteristieken H.S.S. CF met Intelligent Spray Application (I.S.A.) 14

$\begin{array}{ll}2.1 .3 \text { Samenvatting gebruikte spuittechnieken } & 17\end{array}$

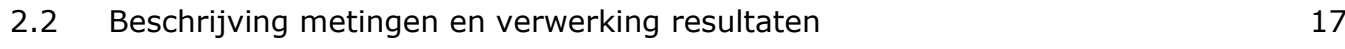

2.2.1 Metingen 17

2.2.2 Analyses 19

2.2.3 Berekeningen en statistiek 20

$\begin{array}{lll}2.3 & \text { Weersomstandigheden } & 22\end{array}$

$\begin{array}{llr}3 & \text { Resultaten } & 23\end{array}$

$3.1 \quad$ Drift naar de grond $\quad 23$

3.2 Drift naar de lucht $\quad 24$

$\begin{array}{llr}4 & \text { Discussie } & \mathbf{2 7}\end{array}$

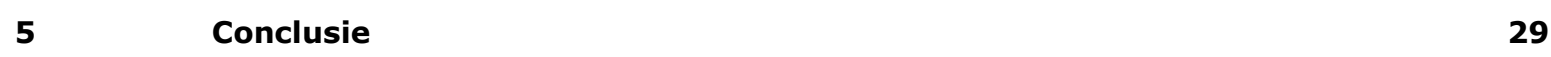

$\begin{array}{ll}\text { Literatuur } & \mathbf{3 0}\end{array}$

Bijlage $1 \quad$ Script statistische analyse $\quad 32$

Bijlage 2 Weersomstandigheden tijdens driftmetingen 33

Bijlage 3 Driftdepositie (\% van afgifte) op de grond naast het gewas 34

Bijlage 4 Driftdepositie (\% van afgifte) naar de lucht 36

Bijlage 5 Achtergrond informatie lijst TCT adviezen en driftarme spuitdoppen 



\section{Woord vooraf}

De emissie van gewasbeschermingsmiddelen verminderen is van groot belang voor de fruitteelt en speelt een belangrijke rol bij de invulling van beleid en regelgeving. Toedieningstechnieken die de drift, het verwaaien van de spuitvloeistof tot buiten het doelgewas, reduceren zijn nodig om de beleidsdoelen te kunnen realiseren en om gewasbeschermingsmiddelen veilig te kunnen gebruiken. In deze rapportage wordt het onderzoek van een driftreducerende techniek in de fruitteelt beschreven. Drift onderzoek is gedaan aan de H.S.S. CF dwarsstroom boomgaardspuit met een H.S.S. Intelligent Spray Application (I.S.A.) systeem. Het H.S.S.-I.S.A. systeem bestaat uit groendetectie sensoren en PWM spuitdophouders voor variabel doseren met gebruikmaking van een $75 \%$ driftreducerende spuitdop en lage luchtondersteuning (1400 rpm ventilator) in het volblad stadium van een appelboomgaard. De driftmetingen zijn uitgevoerd in het drift proefveld voor de fruitteelt, een boomgaard van WageningenUR WPR-Open Teelten Fruit te Randwijk, met medewerking van WageningenUR Unifarm.

Dit onderzoek is uitgevoerd in opdracht van Hol Spraying Systems en begeleid door dhr. H. Hol (H.S.S., Geldermalsen).

Wageningen, november 2020 


\section{Samenvatting}

Met de H.S.S. CF boomgaardspuit met Intelligent Spray Application (I.S.A.); een precisie dwarsstroomspuit die op taakkaart per individuele boom kan spuiten en voorzien van sensoren voor bladgroen- en bladmassadetectie en Pulse Width Modulation (PWM) modules op de dophouders voor precies en variabel doseren, zijn door WageningenUR volgens standaard meetprotocol (TCT en ISO22866) driftmetingen uitgevoerd in vergelijking met de referentie spuit zoals in Nederland gebruikt (Munckhof dwarsstroom met Albuz met ATR lila en 7 bar spuitdruk). De driftmetingen zijn in het groeiseizoen 2019 (augustus-november) en 2020 (juni-juli) op acht meetdagen uitgevoerd bij de bespuiting van de buitenste 8 rijen $(24 \mathrm{~m}$ ) van een appelboomgaard (Elstar). De driftmetingen zijn uitgevoerd in de volblad situatie (BBCH 75-91) van de boomgaard. De H.S.S. CF I.S.A. was tijdens de driftmetingen uitgerust met 75\% driftreducerende spuitdoppen (Lechler IDK 90-015 C bij 3 bar spuitdruk) en was ingesteld op een lage luchtopbrengst van de ventilator (1400 rpm ventilator) welke geregeld en vastgelegd werd door de H.S.S. Drift Control box. Tijdens de driftmetingen werd de buitenste bomenrij 1-zijdig bespoten. Door de constructie van de spuit zuigt de ventilator geen spuitvloeistof aan en blaast daardoor aan de zijde waar niet gespoten wordt geen spuitvloeistof uit.

De resultaten van de driftmetingen zijn gebruikt voor het indelen van de H.S.S. CF I.S.A. precisie boomgaardspuit voorzien van PWM modules op de dophouders met Lechler IDK 90-015 C spuitdoppen (75\% driftreductie), lage luchtinstelling (ventilator toerental $1400 \mathrm{rpm}$ ) en bladgroen- en bladmassadetectie sensoren met enkelzijdige bespuiting van de buitenste bomenrij waarbij het hele perceel werd gespoten. Bij driftmetingen tijdens bespuitingen van een appelboomgaard in het volblad stadium (BBCH 75-91) in vergelijking met een referentie boomgaard bespuiting werd door de H.S.S. CF I.S.A. precisie boomgaardspuit bij een $3 \mathrm{~m}$ teeltvrije zone op de strook 41/2-51/2 $\mathrm{m}$ vanaf de buitenste bomenrij een driftreductie gevonden van $99,0 \%$.

Op grond van dit resultaat kan deze spuittechniek in de driftreducerende techniek (DRT) klasse 99 ingedeeld worden.

De driftreductie naar de lucht, gemiddeld over 0-10 m hoogte op 7,5 m van de laatste bomenrij, geeft de H.S.S. CF I.S.A. precisie boomgaardspuit een driftreductie van $97,6 \%$. 


\section{Summary}

With the H.S.S. CF orchard sprayer and Intelligent Spray Application (I.S.A.); a precision cross-flow fan orchard sprayer equipped with sensors for green leaf detection and Pulse Width Modulation (PWM) functioning nozzles for precise and variable dosing; WageningenUR performed spray drift experiments following the Dutch TCT and ISO22866 protocols. Measurements were done in comparison with a reference spray technique (Munckhof cross-flow fan sprayer with Albuz ATR lilac nozzles at 7 bar spray pressure). Spray drift experiments were done in the 2019 (August - November) and 2020 (June-July) growing season spraying the downwind 8 rows of an apple orchard. Applications were done in eight periods in the full leaf stage of the apples (BBCH 75-91). The H.S.S. CF I.S.A. was equipped with $75 \%$ drift reducing nozzles (Lechler IDK 90-015 $C$ at 3 bar spray pressure) and the air assistance was set in a low setting using the fan at $1400 \mathrm{rpm}$ ) spraying of the outside tree row1-sided. Fan speed was controlled and recorded by the H.S.S. Drift Control box. Because of the construction of the sprayer the fan does not take up any spray liquid and does not blow it out at the side where the nozzles are switched off.

Results of the spray drift experiments are used to quantify spray drift reduction of the H.S.S. CF I.S.A. precision cross-flow fan orchard sprayer equipped with PWM modules at the nozzle bodies, Lechler IDK 90-015 C flat fan venturi nozzles (75\% drift reduction), low air setting (1400 rpm fan) and green leaf detection sensors and single-sided spraying of the outside tree row spraying. To quantify the spray drift reduction the spray drift deposition at 4.5-5.5 $\mathrm{m}$ from the last tree row of the H.S.S CF I.S.A. and its settings is evaluated against the spray drift deposition of the reference spray technique; showing spray drift reduction was $99,0 \%$.

The H.S.S. CF I.S.A. can for the above-mentioned settings be classified in the spray Drift Reducing Technology (DRT) class DRT99.

Measurement of airborne spray drift averaged over 0-10 m height at $7.5 \mathrm{~m}$ distance from the last tree row resulted in a spray drift reduction of $97.6 \%$ when spraying with the H.S.S. CF I.S.A.. 


\section{$1 \quad$ Inleiding}

De emissie van gewasbeschermingsmiddelen verminderen is van groot belang voor de fruitteelt (VW et al., 2007) en speelt een belangrijke rol bij de invulling van Duurzame Gewasbescherming (EZ, 2013), het Activiteitenbesluit Milieubeheer (I\&W, 2017) en de toelating van gewasbeschermingsmiddelen (Ctgb, 2019). Doel van de Nota Duurzame Gewasbescherming (EZ, 2013) is verminderen van de overschrijding van de milieukwaliteitsnormen voor gewasbeschermingsmiddelen in oppervlaktewater tot nagenoeg nul. Hierbij moet het aantal overschrijdingen van de milieukwaliteitsnormen voor gewasbeschermingsmiddelen in oppervlaktewater in 2023 met 90\% afgenomen zijn ten opzichte van die in 2013. Om dit te realiseren moet op alle percelen de toediening van gewasbeschermingsmiddelen met minimaal $75 \%$ driftreducerende technieken (DRT) uitgevoerd worden. Hierbij stelt het Activiteitenbesluit Milieubeheer (I\&W, 2017) dat voor de fruitteelt de teelvrije zone bij een DRT75 minimaal 4,5 m moet zijn. Als een $3 \mathrm{~m}$ teelvrije teeltvrije zone gebruikt wordt moeten gewasbeschermingsmiddelen met een minimaal $90 \%$ driftreducerende techniek (DRT90) uitgevoerd worden.

Daarnaast is ook bij de toelating van gewasbeschermingsmiddelen de driftdepositie op wateroppervlak en de evaluatiezone voor niet-doelwit planten en arthropoden van belang. Het College voor de Toelating van Bestrijdingsmiddelen en Biociden (Ctgb) neemt beslissingen, onder andere op basis van de inschatting van de effecten op het milieu (Ctgb, 2019). Hierbij is het nodig te weten hoeveel van het middel in het oppervlaktewater terecht komt. Het Ctgb heeft de resultaten van emissie-onderzoek (Zande et al., 2019) ingedeeld naar driftreducerende techniek klassen (DRT) opgenomen in een drifttabel (Ctgb, 2019). In Tabel 1.1 is voor de DRT-klassen DRT75 tot DRT99 zoals gebruikt in de fruitteelt voor de kale boom situatie (voor $1 \mathrm{mei}$ ) en de volblad situatie (na 1 mei tot 50\% bladval) in driftdepositie weergegeven bij een teeltvrije zone van $3 \mathrm{~m}$.

Tabel 1.1 Driftdepositie (\% van uitgebracht spuitvolume per oppervlakte-eenheid) op wateroppervlak (3 $\mathrm{m}$ teeltvrije zone, 4,5-5,5 $\mathrm{m}$ vanaf buitenste bomenrij) van driftreducerende technieken (DRT) in verschillende klassen in de kale boom (voor 1 mei) en de volblad (na 1 mei) situatie (naar: Ctgb, 2019).

\begin{tabular}{lrr} 
Driftreducerende techniek groot fruit & Driftpercentage [\%] & kaal \\
\cline { 2 - 3 } Standaard & 16,6 & 8,6 \\
\hline DRT75 & 2,0 \\
\hline DRT90 & 1,0 \\
\hline DRT95 & 2,5 & 0,36 \\
\hline DRT97,5 & 1,3 & 0,13 \\
\hline DRT99 & 1,3 & 0,3 \\
\hline
\end{tabular}

De emissie van gewasbeschermingsmiddelen in de fruitteelt is hoog ten opzichte van andere teeltsectoren. Dit wordt ondermeer veroorzaakt door de opgaande en horizontale spuitrichting en de vaak krachtige luchtondersteuning bij fruitteeltspuiten waardoor veel spuitvloeistof door het bladerdek van de bomenrijen heen gespoten wordt. Om drift te beperken zijn verschillende techniek- en teeltmaatregelen mogelijk. Technische maatregelen kunnen bestaan uit doptype, afscherming en luchtondersteuning. Een teeltmaatregel is bijvoorbeeld het aanleggen van een windsingel (windhaag), of het aanleggen van een teeltvrije zone waardoor de afstand tussen het te bespuiten gewas en het oppervlaktewater vergroot wordt, en de drift naar het wateroppervlak af zal nemen.

Emissie naar de lucht (druppels en damp) bij gewasbespuitingen wordt in de toelating van middelen of het Activiteitenbesluit Milieubeheer momenteel niet in ogenschouw genomen. Uit metingen is gebleken dat bespuitingen met neveldoppen een aanzienlijke drift naar de lucht tot gevolg kunnen hebben (Michielsen et al., 2007, Zande et al., 2014). Deze emissie kan relevant zijn voor milieubelasting op 
grotere afstand van percelen, of consequenties hebben voor de aanwezigheid van bijvoorbeeld omwonenden en bebouwing (Gezondheidsraad, 2014).

In eerder driftonderzoek is aangetoond dat de H.S.S. CF uitgerust met H.S.S. Drift Control uit te rusten met $90 \%$ driftreducerende spuitdoppen en gebruik te maken van een lage luchthoeveelheid bij $1800 \mathrm{rpm}$ van de ventilator de driftreductie 90\% was terwijl de buitenste bomenrij wel van twee zijden bespoten wordt (Stallinga et al., 2017). Werd daarbij ook het H.S.S. AWC systeem gebruikt, voor gescheiden aanpassing van de richting van luchtondersteuning in de bovenwindse en benedenwindse richting, dan was de driftreductie 95\%. In de tussentijd is de ontwikkeling van boomgaardspuiten verder gegaan en is aangetoond dat ook boomgaardspuiten met een lagere spuitdruk, van 3 bar zoals in de akkerbouw gebruikt, ook een goede depositie in de boom kunnen geven (Michielsen et al., 2019; Zande et al., 2020). Bovendien is er de mogelijkheid om op basis van taakkaarten of sensoren alleen die plekken te spuiten die nodig zijn; precisie landbouw. H.S.S. heeft een nieuwe boomgaardspuit ontwikkeld op basis van het H.S.S.-CF platform waarbij door een koppeling met AgroManager taakkaarten ingelezen kunnen worden waarbij op individueel boomniveau besloten kan worden de boom wel of niet te bespuiten. Door een Rometron Pulse Width Modulation (PWM) technologie te gebruiken, zoals gebruikt in de akkerbouw voor het 'spot-spraying' van individuele onkruidplanten op basis van Rometron groendetectie sensoren kunnen de individuele fruitbomen op $10 \mathrm{~cm}$ nauwkeurig bespoten worden. Deze groendetectie sensor - PWM koppeling heeft H.S.S. het Intelligent Spray Application (I.S.A.) systeem genoemd. Uit eerder onderzoek (Wenneker et al., 2003) is gebleken dat groendetectie sensoren gebruikt op een dwarsstroom boomgaardspuit de drift in het volblad stadium met 55\% kunnen reduceren. Door de luchtondersteuning verder te verlagen (1400 rpm van de ventilator) verwacht men bovendien een hogere driftreductie dan gerealiseerd in het eerdere onderzoek met de H.S.S.-CF (Stallinga et al., 2017). De verwachting is dat de H.S.S.-CF boomgaardspuit uitgerust met het H.S.S. Intelligent Spray Application (I.S.A.) systeem, gebruik van Lechler IDK 90-015 C spleetdoppen op 3 bar spuitdruk, een ventilator toerental van 1400 rpm en eenzijdig spuiten van de buitenste bomenrij de driftreductie aanzienlijk verbeterd kan worden en wel $99 \%$ zou kunnen zijn.

\section{Doel van het onderzoek}

Vergelijking van de spuitdrift van de H.S.S. CF boomgaardspuit met H.S.S. Intelligent Spray Application (I.S.A.) met Lechler IDK 90-015 C spleetdoppen op 3 bar spuitdruk (75\% driftreducerende doppen) en aangepaste hoeveelheid luchtondersteuning (1400 rpm ventilator) en eenzijdig spuiten van de buitenste bomenrij met een standaard dwarsstroom boomgaardspuit (Huijsmans et al., 1997; TCT, 2017c). De driftmetingen werden dusdanig opgezet dat de resultaten voldoen aan de opgestelde eisen vanuit de toelating van gewasbeschermingsmiddelen ( $\mathrm{Ctgb}$ ), het Activiteitenbesluit Milieubeheer (I\&W, 2017) en internationale afspraken rondom erkenning van driftmetingen (ISO22866, 2005; ISO22369, 2006).

In deze rapportage worden de uitgevoerde driftmetingen van de H.S.S. CF boomgaardspuit met H.S.S. Intelligent Spray Application (I.S.A.) en de standaard dwarsstroom boomgaardspuit tijdens bespuitingen van een appelboomgaard in het volblad (na 1 mei; $\mathrm{BBCH75-91)} \mathrm{stadium} \mathrm{beschreven.} \mathrm{In}$ hoofdstuk 2 wordt de proefopzet besproken, daarna volgen in hoofdstuk 3, 4 en 5 respectievelijk de resultaten, discussie en conclusies. 


\section{Materiaal en Methode}

\subsection{Afstelling en beschrijving spuittechniek}

In een veldonderzoek is in 2019-2020 de drift vastgelegd van een H.S.S. CF boomgaardspuit met Intelligent Spray Application (I.S.A.); een precisie dwarsstroomspuit voorzien van Rometron sensoren voor bladgroen- en bladmassadetectie en Rometron Pulse Width Modulation (PWM) modules op de dophouders voor precies en variabel doseren. Gecombineerd met de H.S.S. Controlbox GPS kan de spuit daarbij een boomgaard ook op taakkaart spuiten. De taakkaart specificeert welke boom wel en welke boom niet gespoten moet worden. Tijdens de driftmetingen is een taakkaart gebruikt waarbij alle bomen van de boomgaard bespoten werden. De Rometron groendetectie sensoren zorgden ervoor dat hierbij alleen de groene boomdelen gespoten werden. Er werd gespoten met een lage luchtinstelling (1400 rpm ventilator). Bij de bespuitingen werd de drift vastgelegd bij gebruik van Lechler IDK 90-015 C (druk 3 bar, 0,60 l/min), een rijsnelheid van $8 \mathrm{~km} / \mathrm{h}$ en een maximaal spuitvolume van $250 \mathrm{l} / \mathrm{ha}$. De buitenste bomenrij werd enkelzijdig bespoten. De gebruikte Lechler IDK 90-015 C spuitdop staat bij de gebruikte spuitdruk van 3 bar nu in de driftreducerende doppenlijst (TCT, 2020) als een 75\% driftreducerende spuitdop (DRD75). Bij een maximale druk van 2 bar is deze spuitdop nu in de DRD-lijst aangegeven als een DRD90.

De drift van de H.S.S.-CF I.S.A. precisie boomgaardspuit werd vergeleken met die van de Munckhof dwarsstroomspuit voorzien van Albuz ATR Lila doppen (referentietechniek; Huijsmans et al., 1997; TCT, 2017c). In paragraaf 2.1.1 staan karakteristieken beschreven van de in de proeven gebruikte Munckhof standaard boomgaardspuit en in paragraaf 2.1.2 staat een beschrijving van de H.S.S.-CF I.S.A. precisie boomgaardspuit. In paragraaf 2.1.3 staat een samenvattend overzicht van de gebruikte spuittechnieken.

\subsubsection{Karakteristieken Munckhof standaard boomgaardspuit}

De in Nederland voor driftonderzoek gebruikte standaard boomgaardspuit is de Munckhof dwarsstroomspuit (Huijsmans et al., 1997; TCT, 2017c). De Munckhof dwarsstroomspuit is een axiaalspuit voorzien van een dwarsstroomkap op de ventilator (Figuur 2.1).

In Tabel 2.1 staan de posities van de tien dophouders van de Munckhof dwarsstroomspuit boven grondoppervlak weergegeven.

Tabel 2.1 Dophoogte vanaf de grond [cm] van de dophouders op de Munckhof dwarsstroomspuit.

\begin{tabular}{llllllllllll} 
dopnr & 1 & 2 & 3 & 4 & 5 & 6 & 7 & 8 & 9 \\
links & 50 & 68 & 84 & 99 & 120 & 153 & 180 & 215 & 250 & 285 \\
\hline rechts & 48 & 66 & 81 & 99 & 121 & 153 & 181 & 216 & 251 & 286 \\
\hline
\end{tabular}

Er werd gespoten met $2 \times 8$ geopende spuitdoppen, waarbij de onderste $(50 \mathrm{~cm})$ en de bovenste dop (op $285 \mathrm{~cm}$ ) waren gesloten. De bovenste spuitende dop zat op 2,50 m hoogte in overeenstemming met de toppen van de fruitbomen. De spuit werd aangedreven door een New Holland T4050N (2019) en een New Holland T4.110N (2020) fruitteelt trekker, met een rijsnelheid van 6,5-6,9 km/h en een aftakas toerental van $540 \mathrm{rpm}$.

Er werd gemeten bij de vollucht stand van de ventilator, hierbij was de gemiddelde luchtsnelheid links en rechts over de gehele luchtspleet $21 \mathrm{~m} / \mathrm{s}$. Bij de bespuitingen werd de drift vastgelegd bij gebruik van Albuz ATR Lila werveldoppen en een spuitdruk van 7 bar (referentie) en een spuitvolume van 200 l/ha. 


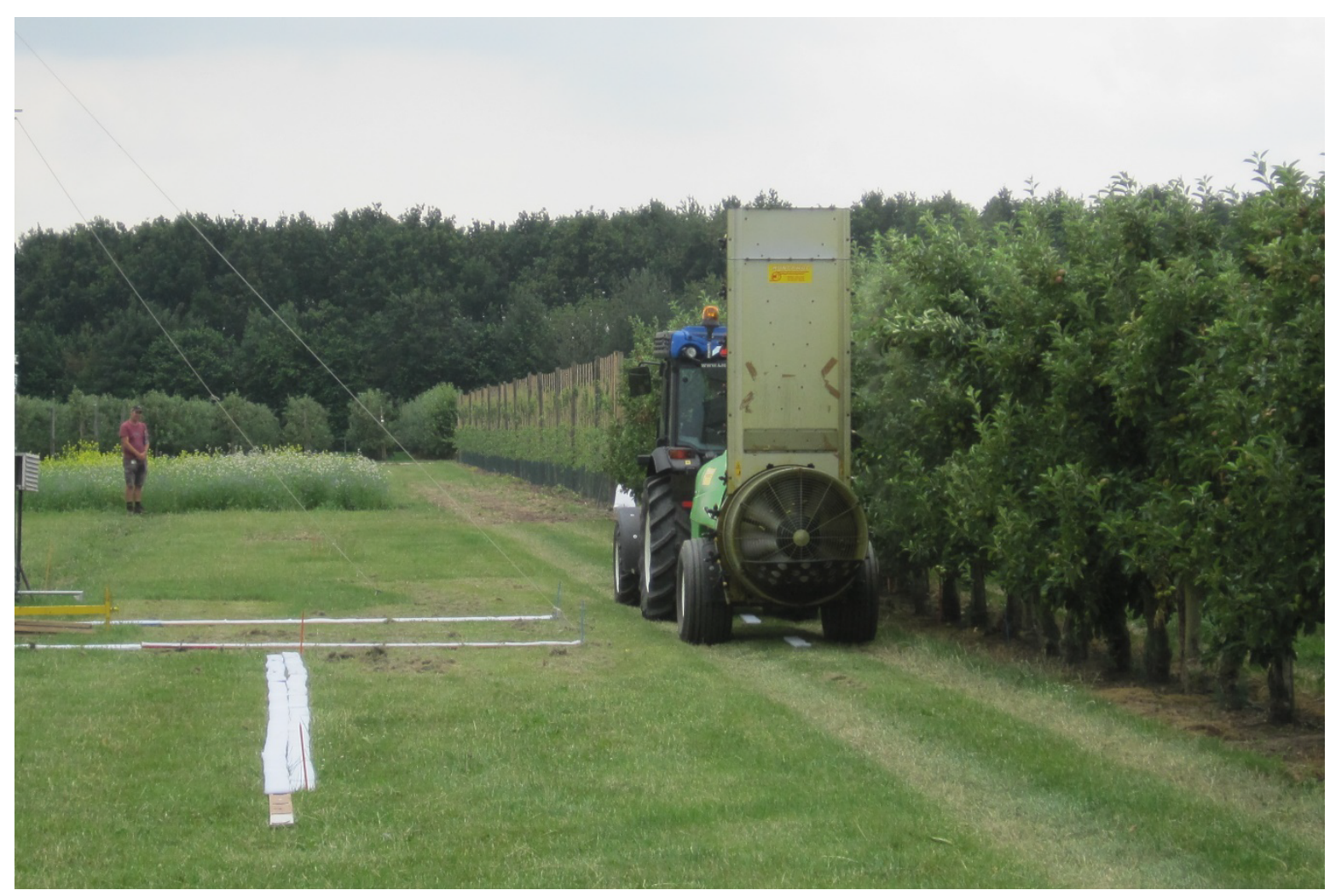

Figuur 2.1 Standaard boomgaardspuit (Munckhof dwarsstroom) tijdens driftmetingen.

\subsubsection{Karakteristieken H.S.S. CF met Intelligent Spray Application (I.S.A.)}

De H.S.S. CF met Intelligent Spray Application (I.S.A.) is een precisie dwarsstroom boomgaardspuit met een centrifugaalventilator met slangen naar blaasmonden op een dwarsstroomtoren (Figuur 2.2). Door de constructie van de spuit zuigt de ventilator geen spuitvloeistof aan en blaast daardoor aan de zijde waar niet gespoten wordt geen spuitvloeistof uit. Het is daardoor niet nodig de blaasmonden af te sluiten aan de kant waar niet wordt gespoten. Aan weerszijden op de dwarsstroomtoren zitten acht blaasmonden met per blaasmond een Rometron Pulse Width Modulation (PWM) module in plaats van de membraanafsluiter op de ARAG wisseldophouder voor drie spuitdoppen (Figuur 2.2, Tabel 2.2).

De luchtondersteuning kan hoog en laag ingesteld worden door middel van een handel (Figuur 2.4). Tijdens de driftmetingen stond de luchtondersteuning in de lage stand. Het toerental van de ventilator kan met de H.S.S. Controlbox ingesteld worden en tijdens de bespuiting vastgelegd (Figuur 2.3) worden en was tijdens de driftmetingen $1400 \mathrm{rpm}$.
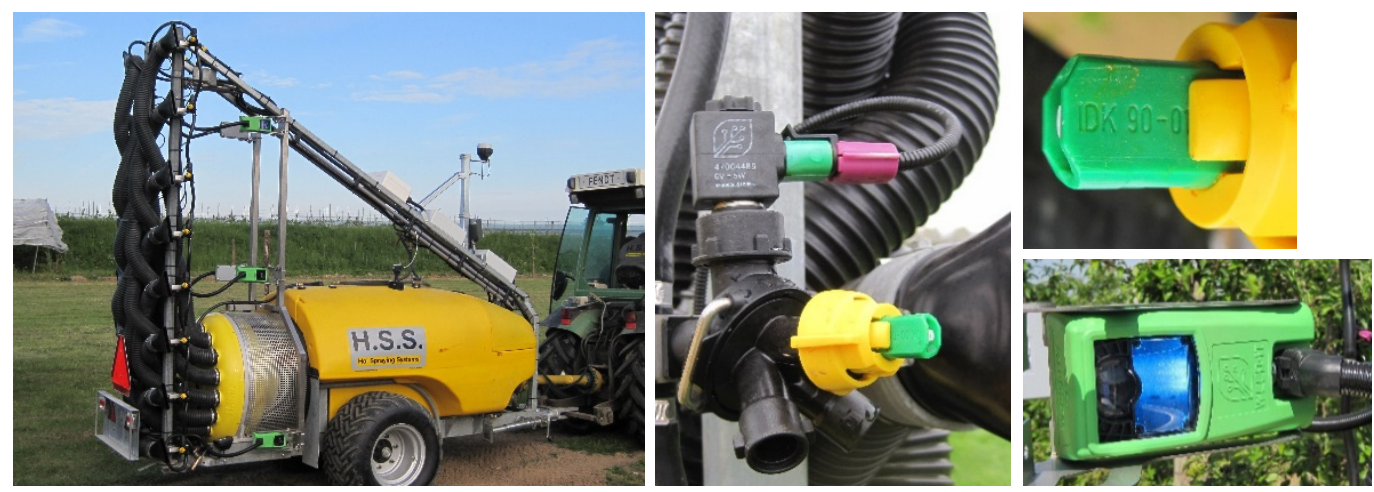

Figuur 2.2 H.S.S.-CF I.S.A. precisie dwarsstroomspuit (links) met GPS, Rometron sensoren voor bladgroen- en bladmassa detectie (rechts onder) en Rometron Pulse Width Modulation (PWM) module (midden) op de drieling dophouder met daarin een Lechler IDK 90-015 C venturi spleetdop (rechts boven) voor iedere blaasmond. 
De druk van de spuitdoppen wordt met de H.S.S. Controle box met de optie H.S.S. Drift Control en een digitale drukmeter ingesteld en vastgelegd (Figuur 2.3).
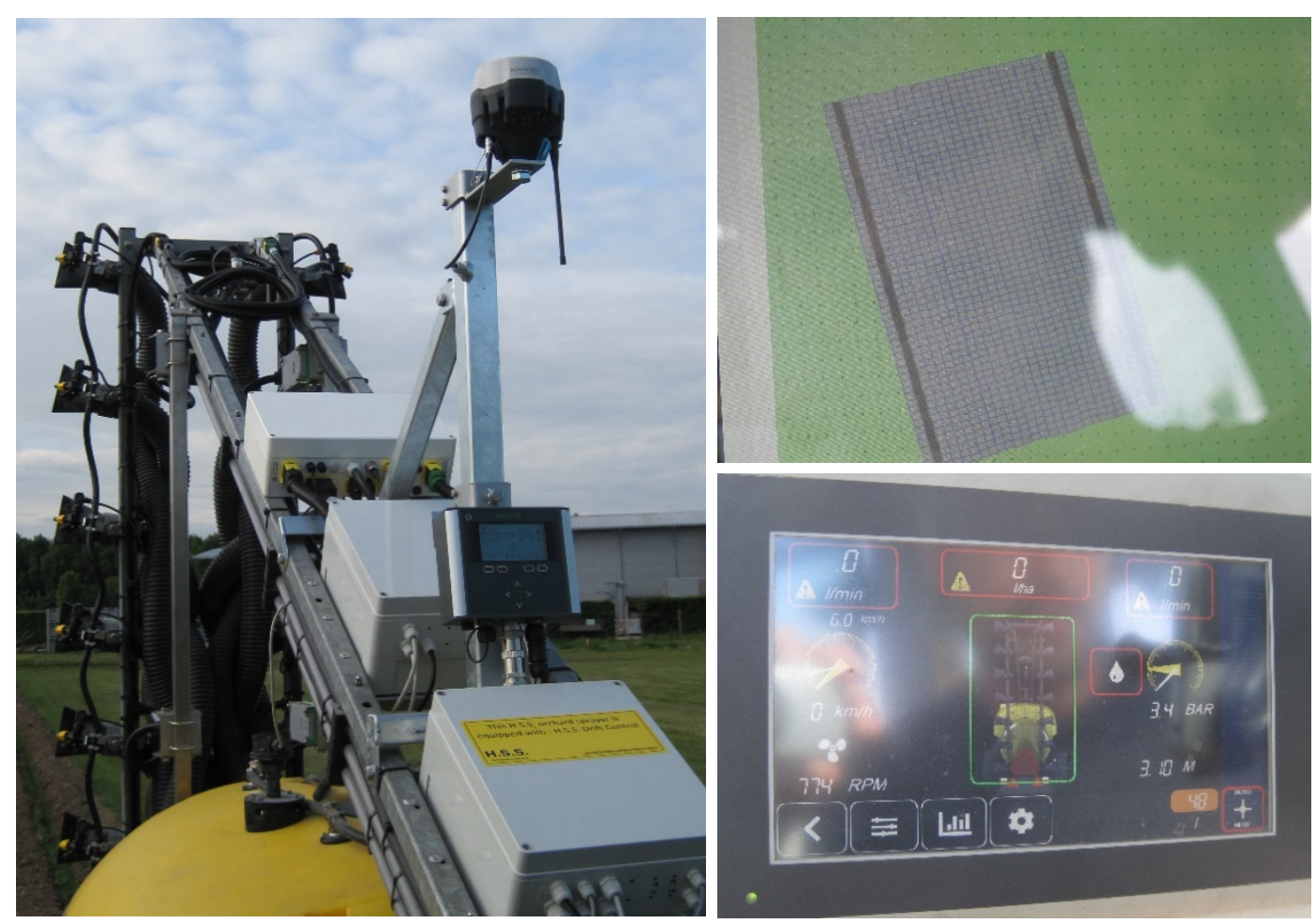

Figuur 2.3 Controller units voor de precisie aansturing op de H.S.S. -CF I.S.A. precisie boomgaardspuit met GPS sensor en Rometron spuitcomputer voor aansturing van de Rometron bladgroen- en bladmassadetectie sensoren en PWM elementen (links) en screenshots van de taakkaart (rechts boven, ieder vakje is een halve boom ter bepaling van wel/niet bespuiten) en van de H.S.S. Controlbox voor de aansturing en registratie van ventilator toerental en spuitdruk (rechts onder).

De spuit was aan beide kanten met 8 spuitdoppen uitgerust. Er werd gespoten met 2 × 8 geopende spuitdoppen, waarbij alle spuitdoppen met de groendetectie sensoren aan en uitgeschakeld werden als er wel/niet bladgroen aanwezig was. Hierdoor werd de inschakeling van de hoogste spuitdop automatisch bepaald door de sensoren, alsook het aan/uit schakelen aan het begin en aan het eind van de bomenrij. Aan beide kanten van de spuit zaten daarvoor drie Rometron sensoren met ieder vier kanalen voor bladgroen en bladmassa detectie. Van de onderste sensor waren alleen de bovenste twee kanalen actief en van de bovenste sensor alleen de onderste twee. Van de middelste sensor waren alle vier de kanalen actief waardoor er in totaal acht kanalen actief zijn waarbij ieder kanaal ter hoogte van de spuitdop naar de bladmassa kijkt en die de individuele acht spuitdoppen kunnen schakelen. De PWM controllers van de individuele spuitdoppen zijn direct aan het signaal van het sensorkanaal gekoppeld waardoor ze snel kunnen reageren en in de rijrichting per cm open en dicht kunnen gaan.

In Tabel 2.2 staan de posities van de dophouders op de H.S.S.-CF precisie boomgaardspuit boven grondoppervlak weergegeven.

Tabel 2.2 Dophoogte vanaf de grond [ $\mathrm{cm}]$ van de dophouders op de H.S.S. -CF.

\begin{tabular}{lccccccccc} 
dopnr & 1 & 2 & 3 & 4 & 5 & 6 & 7 & 8 \\
links+rechts & 45 & 76 & 107 & 140 & 171 & 203 & 243 & 283 & \\
\hline
\end{tabular}



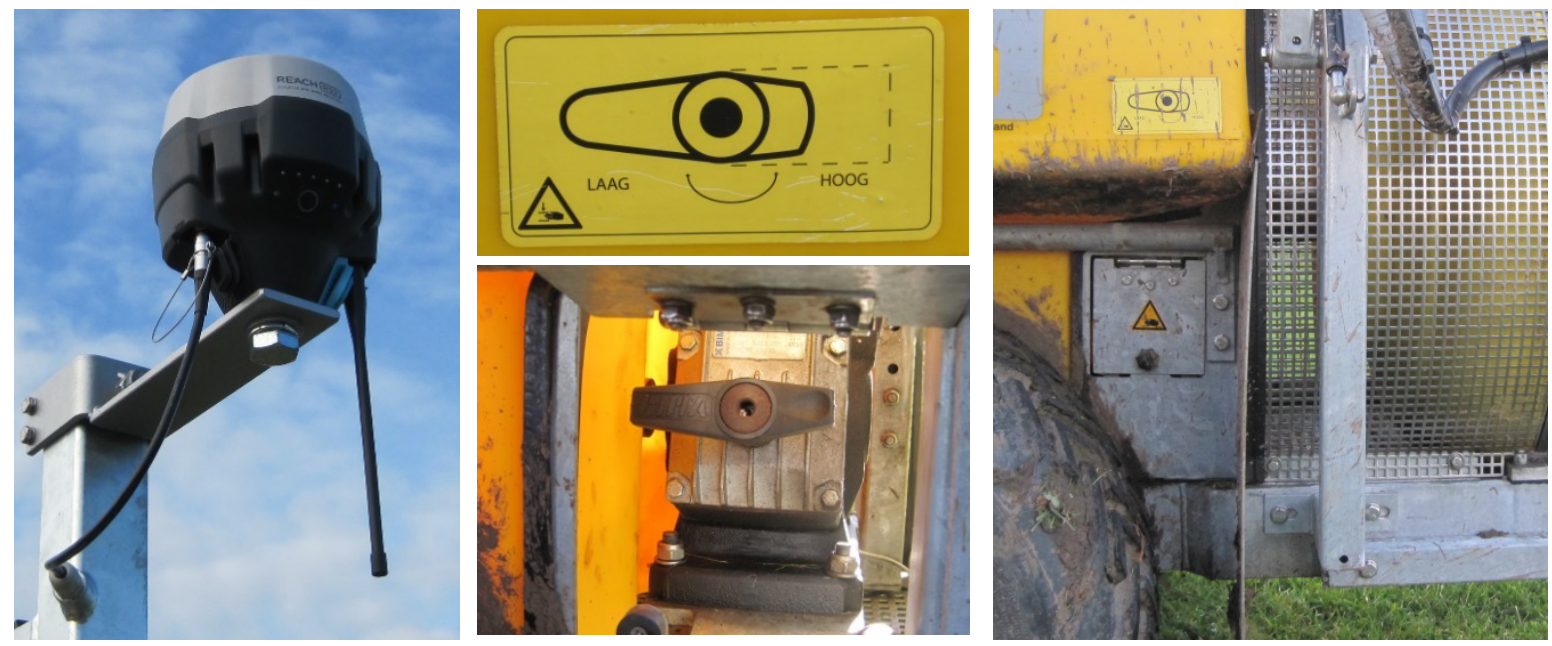

Figuur 2.4 GPS sensor (links) voor plaatsbepaling in de boomgaard en instelling van de lage instelling van de luchtondersteuning (midden, rechts; stand handel achter klep onder tank voor ventilator).

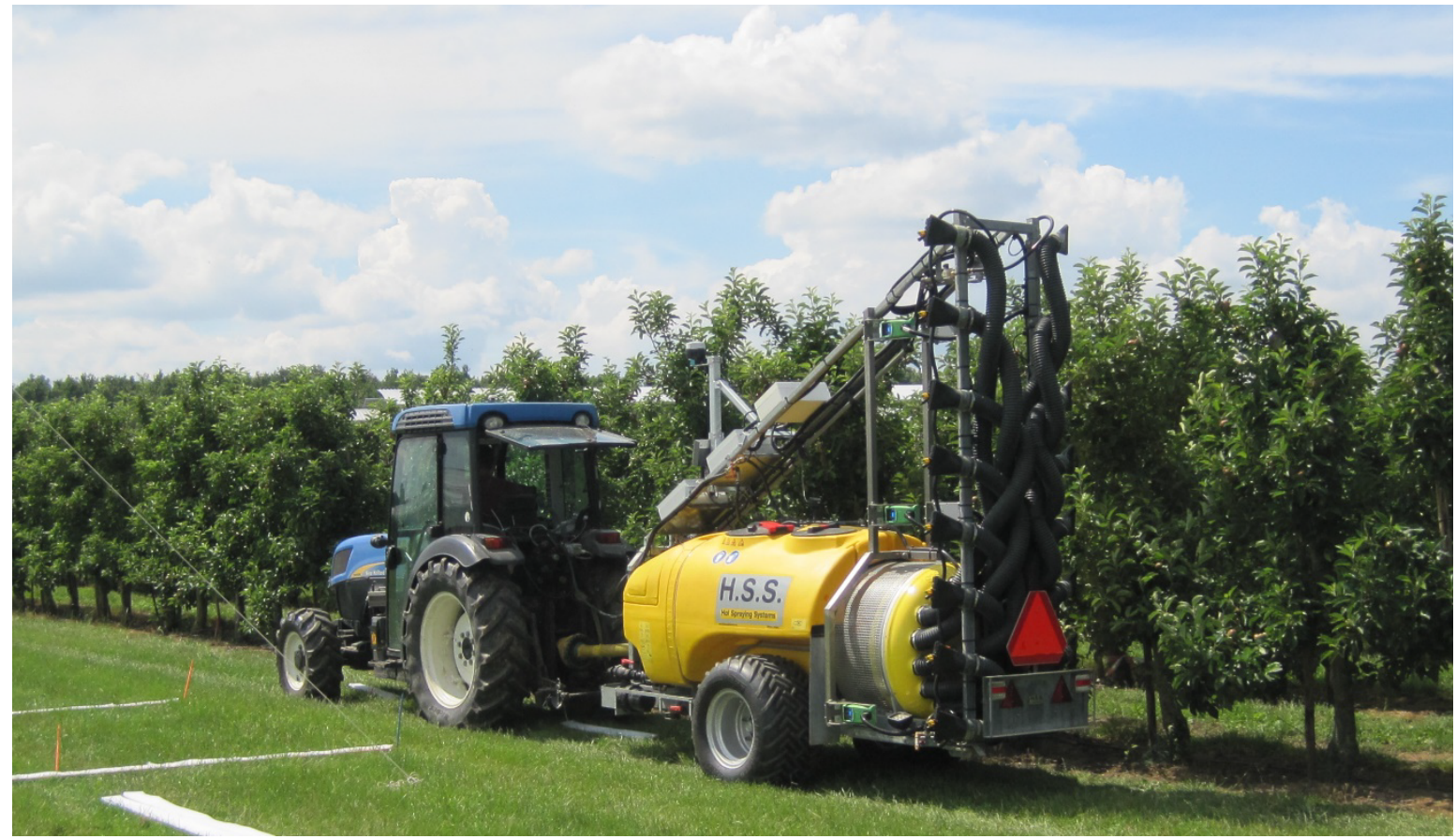

Figuur 2.5 H.S.S.-CF I.S.A. precisie dwarsstroomspuit tijdens driftmetingen.

Tijdens de driftmetingen (Figuur 2.5) werd er gespoten met 2 × 8 spuitdoppen. Het openen van de spuitdoppen werd door de Rometron sensoren automatisch geregeld per individuele spuitdop. De bovenste spuitende dop zat daardoor meestal op 2,43 m hoogte in overeenstemming met de toppen van de fruitbomen. De gaten tussen de toppen van de bomen, of wanneer er een boom in de bomenrij mistte, werden daardoor niet gespoten. Aan het begin van de bomenrij gingen de spuitdoppen automatisch één voor één spuiten bij detectie van bladgroen van de bomen en aan het eind van de bomenrij op dezelfde wijze dicht. De dophouders zaten gekoppeld aan Rometron Pulse Width Modulation (PWM) controllers (Figuur 2.2) die de spuitdoppen binnen de $10 \mathrm{~cm}$ rijafstand konden aanen uitschakelen. Met het H.S.S. Controlbox GPS kan het gehele systeem op basis van een taakkaart (Figuur 2.3) aangestuurd worden waarbij per individuele fruitboom (1 $\mathrm{m}$ in de rijlengte) gespoten kan worden. Voor de driftmetingen is een taakkaart gebruikt waarbij de gehele boomgaard werd bespoten.

De spuit werd aangedreven door een New Holland T4050N (2019) en een New Holland T4.110N (2020) fruitteelt trekker. De rijsnelheid bij een aftakastoerental van $400 \mathrm{rpm}$ was 8,0 km/h. De drift werd gemeten bij de lage luchtinstelling van de ventilator (Figuur 2.4) en $1400 \mathrm{rpm}$ van de ventilator. 
Bij de bespuitingen werd de drift vastgelegd bij gebruik van Lechler IDK 90-015 C spuitdoppen (Figuur 2.2) bij een druk van 3 bar. Het spuitvolume was $250 \mathrm{l} / \mathrm{ha}$.

\subsubsection{Samenvatting gebruikte spuittechnieken}

In Tabel 2.3 staat een samenvatting van de tijdens de driftmetingen gebruikte spuittechnieken.

Tabel 2.3 Samenvatting gebruikte spuittechnieken in de driftmetingen.

\begin{tabular}{lcc} 
Spuit & Munckhof dwarsstroom & H.S.S.-CF I.S.A. dwarsstroomspuit \\
lucht & vol & laag \\
\hline Aftakas [rpm] & 540 & 400 \\
\hline Ventilator [rpm] & 2100 & 1400 \\
\hline Spuitdoppen & Albuz & Lechler \\
\hline & ATR Lila & IDK 90-015 C \\
\hline doptype & Werveldop & Spleetdop \\
\hline druk [bar] & 7 & 3 \\
\hline n-doppen & $2 \times 8$ & $2 \times 8$ \\
\hline dop afgifte [l/min] & 0,42 & 0,60 \\
\hline rijsnelheid [km/h] & 6,9 & 8,0 \\
\hline spuitvolume $[\mathrm{l} / \mathrm{ha}]$ & 200 & 250
\end{tabular}

\subsection{Beschrijving metingen en verwerking resultaten}

\subsubsection{Metingen}

De driftmetingen werden uitgevoerd in 2019-2020. In 2019 was dat op 22 augustus en 15 november. In 2020 werden de metingen uitgevoerd op 11 juni, 19 juni, 2 juli, 3 juli, 23 juli en 28 juli. De metingen werden gedaan op de proeftuin van WPR-Open Teelten-fruit te Randwijk, op perceel Oost in overeenstemming met de driftmeetprotocollen TCT (2017) en ISO22866. Dit perceel is aangeplant met het appelras Elstar. De fruitbomen staan in een plantverband van 1,10 m afstand in de rij en $3 \mathrm{~m}$ tussen de rijen (rijafstand). De bomen waren 2,25 m hoog en in het volblad stadium (BBCH 90).

In 2019 bestond het perceel uit een blok van 110 meter lengte en 14 rijen (52m) breed. Daaromheen lag een strook gras van ongeveer $30 \mathrm{~m}$ breed. Op deze strook gras werden twee driftmeetstroken uitgelegd. Bij elke driftmeetstrook werden twee meetraaien (duplo bepalingen) uitgelegd met ongeveer 2 meter tussenruimte tussen de meetraaien. In 2019 werden in het meetgedeelte naast het perceel 2 herhalingen van de driftmeetstroken achter elkaar gelegd, op een onderlinge afstand van $30 \mathrm{~m}$.

In 2020 was de helft van het perceel vervangen door een nieuwe aanplant (zuidzijde). De driftmetingen werden uitgevoerd in het blok met de oude aanplant (noordzijde). Het blok had in 2020 een lengte van $60 \mathrm{~m}$. Op de strook gras kon in 2020 maar 1 meetstrook worden uitgelegd.

In Figuur 2.6 staat een schematische weergave van het proefveld in 2019 (boven) en 2020 (onder). In Figuur 2.7 staan twee dronebeelden met een bovenaanzicht van het proefveld met aan weerszijden de meetopstelling (boven) en een bovenaanzicht van de boomrijen en de proefopstelling.

Tijdens de driftmetingen werden de laatste acht bomenrijen ( $24 \mathrm{~m}$ ) aan de benedenwindse zijde volledig bespoten. Met één en dezelfde instelling werd steeds het blok van acht boomrijen bespoten.

Op de volgende posities werden collectoren (Technofil TF $290 ; 10 \times 100 \mathrm{~cm}, 10 \times 50 \mathrm{~cm}$ ) gelegd om de driftdepositie naar de grond te meten:

- Op 1,5 meter, evenwijdig aan de buitenste bomenrij, een collector van 1 meter lengte.

- Op 3 - 15 meter aaneengesloten collectoren van 0,5 meter (haaks op de bomenrij).

- Op 20 en 25 meter een collector van 1 meter (haaks op de bomenrij). 
De afstand werd gemeten vanaf het midden (hart) van de buitenste bomenrij.

De emissie naar de lucht werd op 7,5 m vanaf de laatste bomenrij met behulp van een mast van $10 \mathrm{~m}$ hoogte gemeten, met twee lijnen met op elke meter hoogte een driftbolcollector (Siral

Abdriftkollektoren art.nr. 00131).

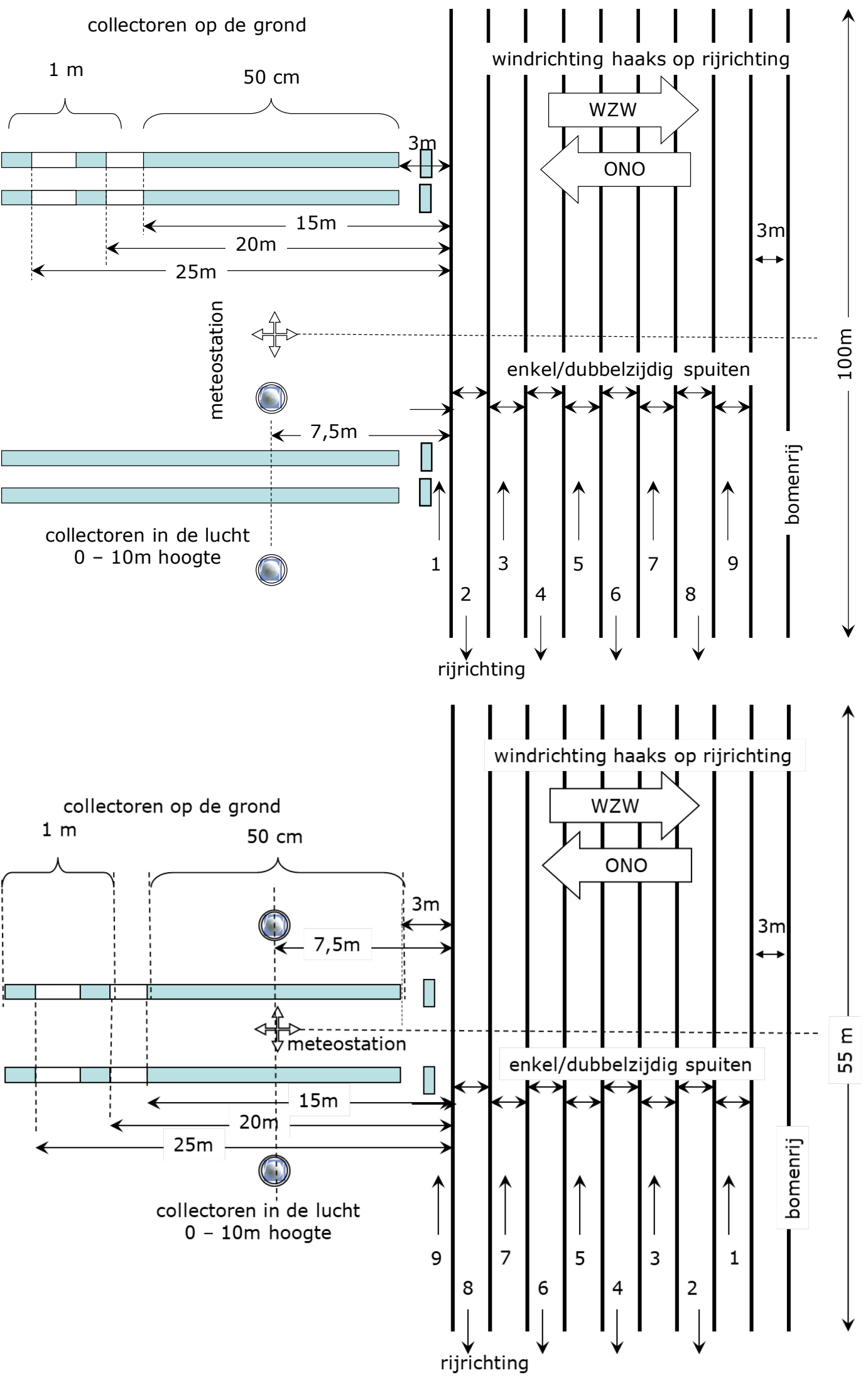

Figuur 2.6 Schematische weergave proefveld en meetopstelling in 2019 (boven) en 2020 (onder). 

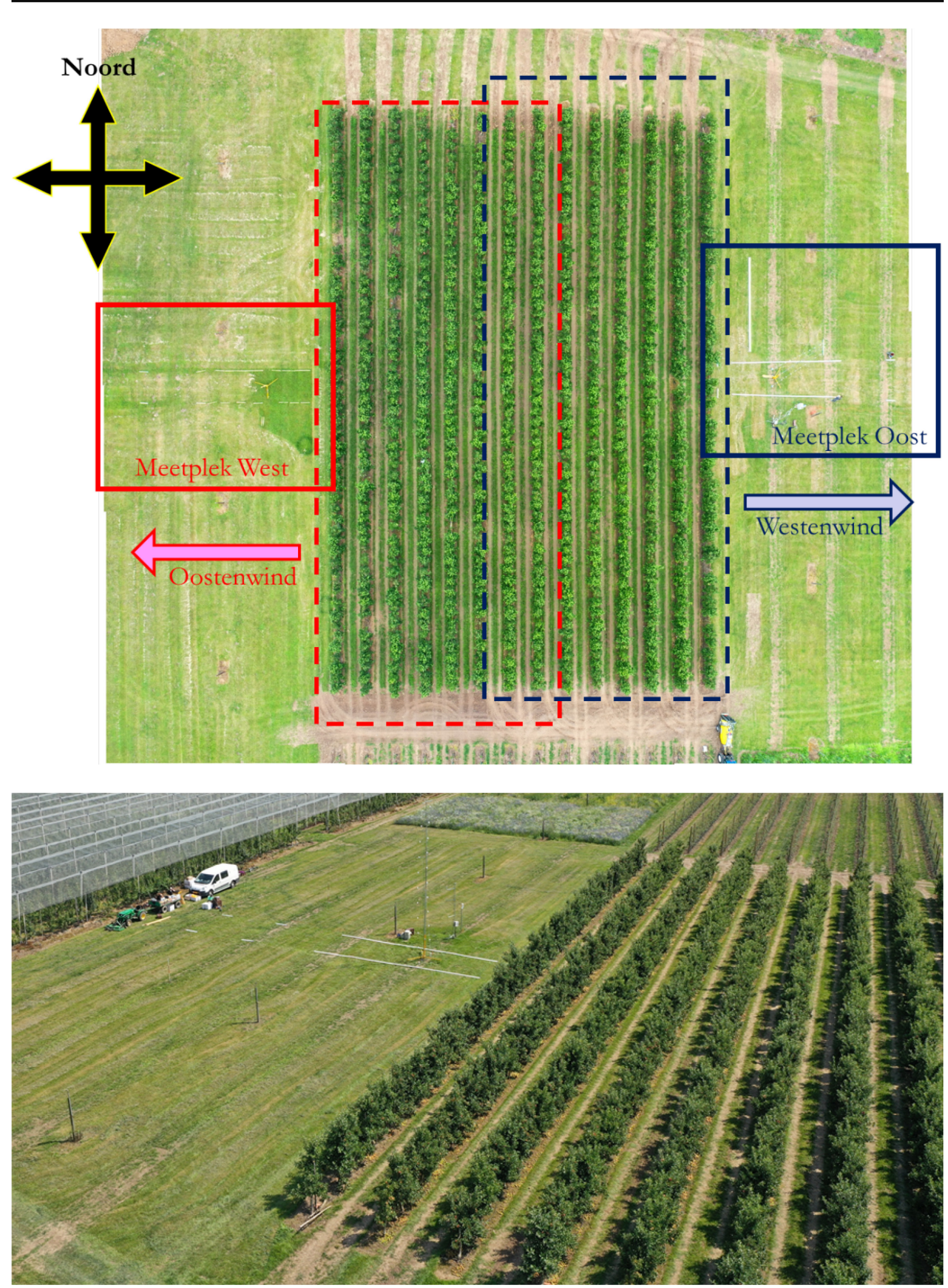

Figuur 2.7 Bovenaanzicht proefveld (boven) en van de boomrijen en meetopstelling.

\subsubsection{Analyses}

De bespuitingen werden uitgevoerd met water waaraan Acid Yellow 250 (AY250, DC Fine Chemicals, C.I. 56205, 2-5 g/I) en een niet-ionische uitvloeier (Agral Gold, 0,075 ml/l) was toegevoegd.

$\mathrm{Na}$ de bespuiting werden de collectoren verzameld en gecodeerd voor verdere analyse op de hoeveelheid AY250. Elke meetdag werden ook monsters genomen uit de tank van de spuit om de AY250-concentratie van de verspoten spuitvloeistof te meten. In het laboratorium werden de 
collectoren met gedemineraliseerd water gespoeld, zodanig dat de AY250 in oplossing kwam. Van deze oplossing werd de concentratie aan AY250 gemeten met behulp van een fluorimeter (Perkin Elmer FL 8500; $\lambda_{\mathrm{ex}}=450 \mathrm{~nm} ; \lambda_{\mathrm{em}}=500 \mathrm{~nm}$ ). Voor het bepalen van de achtergrondfluorescentie werden blanco collectoren geanalyseerd. De concentratie AY250 in de tankmonsters werd ook fluorimetrisch bepaald.

\subsubsection{Berekeningen en statistiek}

De concentratie werd omgerekend naar volume spuitvloeistof per oppervlakte-eenheid. Het percentage drift is berekend door de driftdepositie per oppervlakte-eenheid uit te drukken in procenten van de door de spuitdoppen in het perceel verspoten hoeveelheid vloeistof per oppervlakte-eenheid.

De gemeten fluorescentiewaarde werd omgerekend naar de driftdepositie $\left(\mu \mathrm{l} / \mathrm{cm}^{2}\right)$ volgens:

$$
D_{\text {monster }}=\frac{\left(F_{\text {monster }}-F_{\text {demi }}-F_{\text {blanco }}\right) \times f_{i j k} \times V_{\text {spoel }}}{C_{\text {tm }} \times A_{\text {monster }}}
$$

$\mathrm{D}=$ depositie in $\mu \mathrm{l} / \mathrm{cm}^{2}$;

$\mathrm{F}=$ fluorescentiewaarde;

$\mathrm{F}_{\text {monster }}=$ fluorescentiewaarde van het monster;

$\mathrm{F}_{\text {demi }}=$ fluorescentiewaarde van demiwater;

$\mathrm{F}_{\text {blanco }}=$ bijdrage van de achtergrond door collector;

$\mathrm{f}_{\mathrm{ijk}}=\mathrm{ijkfactor} ; \mathrm{V}_{\text {spoel }}=$ extractievolume in liter;

$\mathrm{C}_{\mathrm{tm}}=$ spuitvloeistofconcentratie in tank in $\mathrm{g} . \mathrm{I}^{-1}$;

$\mathrm{A}_{\text {monster }}=$ monsteroppervlak in $\mathrm{cm}^{2}$.

Vervolgens werd per monster de driftdepositie uitgedrukt als percentage van het uitgebracht spuitvolume volgens:

$$
P=\frac{D_{m}}{Q / 100} \times 100 \%
$$

$\mathrm{P}=$ percentage drift van het uitgebrachte spuitvolume;

$D_{m}=$ driftdepositie in $\mu \mathrm{l} / \mathrm{cm}^{2}$;

$\mathrm{Q}=$ spuitvolume in $\mathrm{l} / \mathrm{ha}$.

Voor de vergelijking van de driftdepositie van de verschillende spuittechnieken zijn de driftwaarden (\% van spuitvolume) uitgerekend voor verschillende evaluatiestroken overeenkomend met de positie van de sloot (insteek-insteek afstand $4 \mathrm{~m}$ ) en het wateroppervlak daarbinnen $(1 \mathrm{~m})$. De teeltvrije zone wordt in het Activiteitenbesluit Milieubeheer (I\&M, 2012) gedefinieerd als de afstand tussen de insteek van de sloot en de buitenste gewasrij (voor fruitteelt $3 \mathrm{~m}$ in Figuur 2.8).

De volgende evaluatiestroken worden onderscheiden:

- slootoppervlak: 3-7, 41/2-81/2, 6-10 en 9-13 m, bij respectievelijk 3, 41/2, 6 en $9 \mathrm{~m}$ teeltvrije zone.

- wateroppervlak: 41/2-51/2, 6-7, 71/2-81/2,101/2-111/2, bij respectievelijk 3, 41/2, 6 en 9 m teeltvrije zone.

- naar de lucht: gemiddeld over $10 \mathrm{~m}$ hoogte op 7,5 m vanaf de laatste bomenrij 


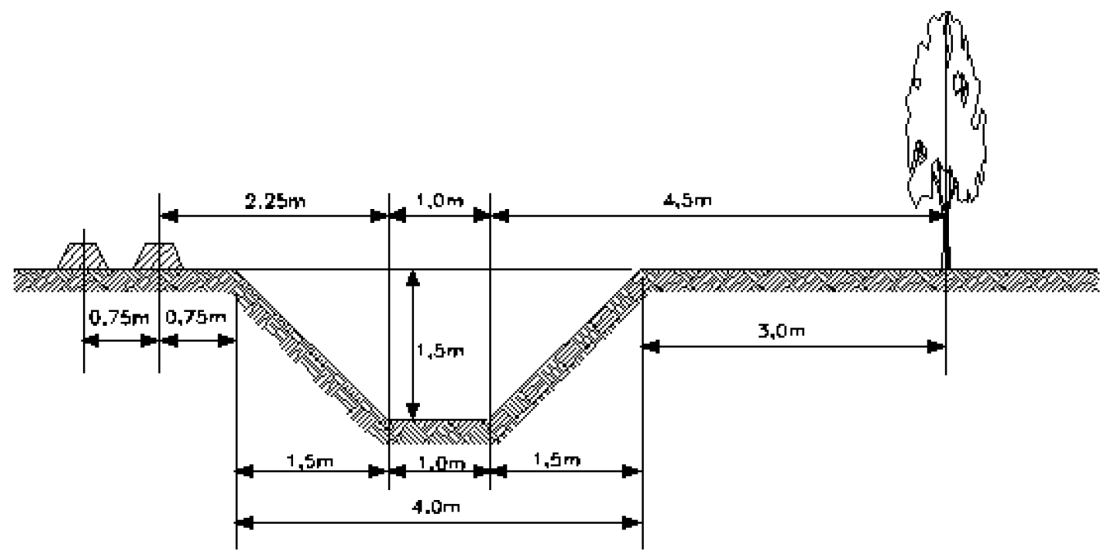

Figuur 2.8 Schematische weergave van de plaats van de sloot, het talud en het wateroppervlak ten opzichte van de laatste gewasrij in aardappelen (links) en de buitenste bomenrij in de fruitteelt (rechts) (Huijsmans et al., 1997).

De gekozen zones van $3 \mathrm{~m}, 41 \frac{1}{2} \mathrm{~m}, 6 \mathrm{~m}$ en $9 \mathrm{~m}$ komen overeen met de in artikel 3.80 van het Activiteitenbesluit Milieubeheer (I\&M, 2012) genoemde zones. Daarbij is $9 \mathrm{~m}$ de teeltvrije zone waarbij een bespuiting nog met een standaard spuittechniek uitgevoerd mocht worden. De zones $3 \mathrm{~m}$ en $41 / 2 \mathrm{~m}$ gelden nu (I\&W, 2017) als teeltvrije zone als de bespuiting uitgevoerd wordt met resp. een $90 \%$ (DRT90) en een 75\% (DRT75) driftbeperkende techniek of maatregel. Voorheen gold voor de kopakker een minimale teeltvrije zone van $6 \mathrm{~m}$ en is deze afstand nu nog ter informatie opgenomen.

Voor het bepalen van de achtergrondfluorescentie worden blanco collectoren geanalyseerd. Het resultaat van deze metingen is een gemiddelde achtergrondfluorescentie van de blanco collectoren met een bijbehorende standaardafwijking. Bij de berekeningen van de driftdepositie (volgens bovenstaande formules) wordt het gemiddelde van de achtergrondfluorescentie gebruikt. Bij de experimenten werden een paar lage driftdeposities gemeten met fluorescentiewaarden dicht of zelfs onder de gemiddelde achtergrondfluorescentie. Berekende driftdeposities kunnen dan zelfs lager dan $0 \%$ worden. De drempelwaarde die in dit rapport aangehouden is, is de fluorescentiewaarde overeenkomend met twee keer de standaardafwijking van de blanco. Deze drempelwaarde is omgerekend naar driftdepositie volgens bovenstaande formules. De drempelwaarde is o.a. afhankelijk van de gemeten techniek (spuitvolume), spoelvolume bij de extractie, collectorgrootte en tankconcentratie en kan per meting (herhaling) verschillen. In de bijlagen staan de berekende waarden, ook die onder de drempelwaarde vallen. Getallen die onder de bijbehorende drempelwaarde vallen staan cursief. Als er in het rapport zelf getallen gepresenteerd worden (bv in samenvattende tabel met de afstand) waarbij de gemiddelde gemeten waarde onder de drempelwaarde komt dan wordt dat aangeven met '<drempelwaarde'. Bijvoorbeeld '<0,006'.

De verschillen in driftdepositiewaarden op de evaluatiestroken tussen de verschillende spuittechnieken werden getoetst bij een onbetrouwbaarheidsdrempel van $5 \%$. Statistische analyse vond plaats met behulp van het statistische programma Genstat (Genstat Release 20.1, VSN International, 2019). Bij de statistische analyse werd gebruik gemaakt van de Genstat procedure IRREML (Keen en Engel, 1998). In Bijlage 1 staat het gebruikte IRREML script.

Voor de indeling van de H.S.S.-CF I.S.A. precisie boomgaardspuit voorzien van Rometron PWM spuitdop functionaliteit en sensoren voor groendetectie in driftreductieklassen (ISO22369-1) werd de driftreductie op de gemeten afstanden en de evaluatiestroken berekend ten opzichte van de driftdepositie van de referentie bespuiting met de Munckhof dwarsstroomspuit uitgerust met Albuz ATR Lila doppen volgens:

$\%$ reductie $=\frac{\left(P_{\text {driftref }}-P_{\text {techniek }}\right)}{P_{\text {driftref }}} \times 100 \%$

$\mathrm{P}_{\text {driftref }}=$ Percentage drift referentietechniek en dop (Munckhof dwarsstroom met Albuz ATR Lila spuitdoppen)

$\mathrm{P}_{\text {techniek }}=$ Percentage drift H.S.S.-CF I.S.A. precisie boomgaardspuit. 


\subsection{Weersomstandigheden}

De metingen werden in 2019 uitgevoerd op 22 augustus en 15 november. In 2020 werden de metingen uitgevoerd op 11 juni, 19 juni, 2 juli, 3 juli, 23 juli en 28 juli. In totaal werden 10 herhalingen gemeten. Tijdens de bespuitingen werden de weersomstandigheden vastgelegd door meting van de temperatuur (Pt100 op $0,5 \mathrm{~m}$ en $4 \mathrm{~m}$ hoogte), de luchtvochtigheid (\% RV met een Rhotronic op 1,5 m hoogte), de windrichting ( $0^{0}=$ haaks t.o.v. de bomenrijen) op $10 \mathrm{~m}$ hoogte en de windsnelheid (cupanemometers op $0,5,2,3,4$ en 10m hoogte) met een tijdsinterval van 5 seconden.

De meteomast stond op 7,5 m afstand vanaf de buitenste bomenrij (zie Figuur 2.6). Bij elke passage van de spuit ter hoogte van het midden van de twee meetopstellingen (2019) of de meetopstelling (2020) werd de tijd van de datalogger genoteerd. Later werd uit de verzamelde data vanuit dit passagetijdstip over 15 seconden vóór en 15 seconden ná passeertijdstip de meetwaarde gemiddeld. In Bijlage 2 staan de resultaten van de metingen van de weersomstandigheden vermeld.

Alle metingen voldoen aan de eisen voor de weersomstandigheden van het meetprotocol (TCT, 2017b). De temperatuur op $4 \mathrm{~m}$ hoogte lag tussen de 5,4 en de $24,6{ }^{\circ} \mathrm{C}$, de windsnelheid op $4 \mathrm{~m}$ hoogte (ongeveer $1 \mathrm{~m}$ boven de boomhoogte) lag tussen de 1,9 en 4,3 m/s en de windhoek was tussen de -19 en 24 graden ten opzichte van dwars op de bomenrij. De gemiddelde weersomstandigheden van de metingen staan in Tabel 2.4.

Tabel 2.4 Gemiddelde weersomstandigheden voor de verschillende technieken tijdens de driftmetingen.

\begin{tabular}{|c|c|c|c|c|c|c|c|c|c|c|}
\hline \multirow[t]{2}{*}{ techniek } & \multirow[t]{2}{*}{$\begin{array}{c}\text { n- } \\
\text { herhalingen }\end{array}$} & \multicolumn{2}{|c|}{$\begin{array}{c}\text { temperatuur } \\
{\left[{ }^{\circ} \mathrm{C}\right] \text { op }} \\
\end{array}$} & \multirow[t]{2}{*}{$\%$ RV } & \multicolumn{2}{|l|}{$\begin{array}{l}\text { windhoek } \\
\text { tov haaks }\end{array}$} & \multicolumn{4}{|c|}{ windsnelheid $[\mathrm{m} / \mathrm{s}]$ op } \\
\hline & & $0,5 \mathrm{~m}$ & $4 m$ & & haaks $=0^{\circ}$ & $0,5 \mathrm{~m}$ & $2 \mathrm{~m}$ & $3 \mathrm{~m}$ & $4 m$ & $10 \mathrm{~m}$ \\
\hline \multirow[t]{2}{*}{ H.S.S.-CF } & & 19,3 & 18,1 & 54 & 2 & 1,0 & 1,5 & 2,2 & 2,6 & 4,0 \\
\hline & gemiddeld & 19,7 & 18,4 & 53,8 & 0 & 1,1 & 1,6 & 2,3 & 2,7 & 4,2 \\
\hline
\end{tabular}

$*=$ geen gemiddelde door defect sensor

Tijdens de driftmetingen was de gemiddelde temperatuur $18,4^{\circ} \mathrm{C}$ (op $4 \mathrm{~m}$ hoogte), de gemiddelde windhoek $0^{\circ}$ ten opzichte van loodrecht op de bomenrij en de gemiddelde windsnelheid op $2 \mathrm{~m}$ hoogte $1,6 \mathrm{~m} / \mathrm{s}$ en op $4 \mathrm{~m}$ hoogte (ongeveer $1 \mathrm{~m}$ boven de bomen) $2,7 \mathrm{~m} / \mathrm{s}$. 


\section{Resultaten}

\subsection{Drift naar de grond}

De resultaten van de metingen van de drift naar de grond naast het perceel zijn weergegeven in Bijlage 3. De gemiddelde drift per spuittechniek tijdens bespuitingen in de volblad situatie ( $\mathrm{BBCH} 75-$ 91) staat weergegeven in Figuur 3.1 en in Tabel 3.1

In Bijlage 3 is te zien dat bij de herhalingen 6, 9 en 10 van de H.S.S.-CF I.S.A. er een groot verschil is tussen de twee rijen met collectoren terwijl er ongeveer maar $2 \mathrm{~m}$ afstand tussen de rijen is. Op de strook 41/2-51/2 m wordt bij rij 1 meer dan 2 keer zoveel driftdepositie gevonden als bij rij 2. Op grond van ervaring bij andere driftmetingen lijken deze metingen onbetrouwbaar en zijn van de herhalingen 6 en 9 alleen de metingen van de eerste rij collectoren en van herhaling 10 beide rijen collectoren niet meegenomen in de beschrijving van de resultaten (zie discussie).

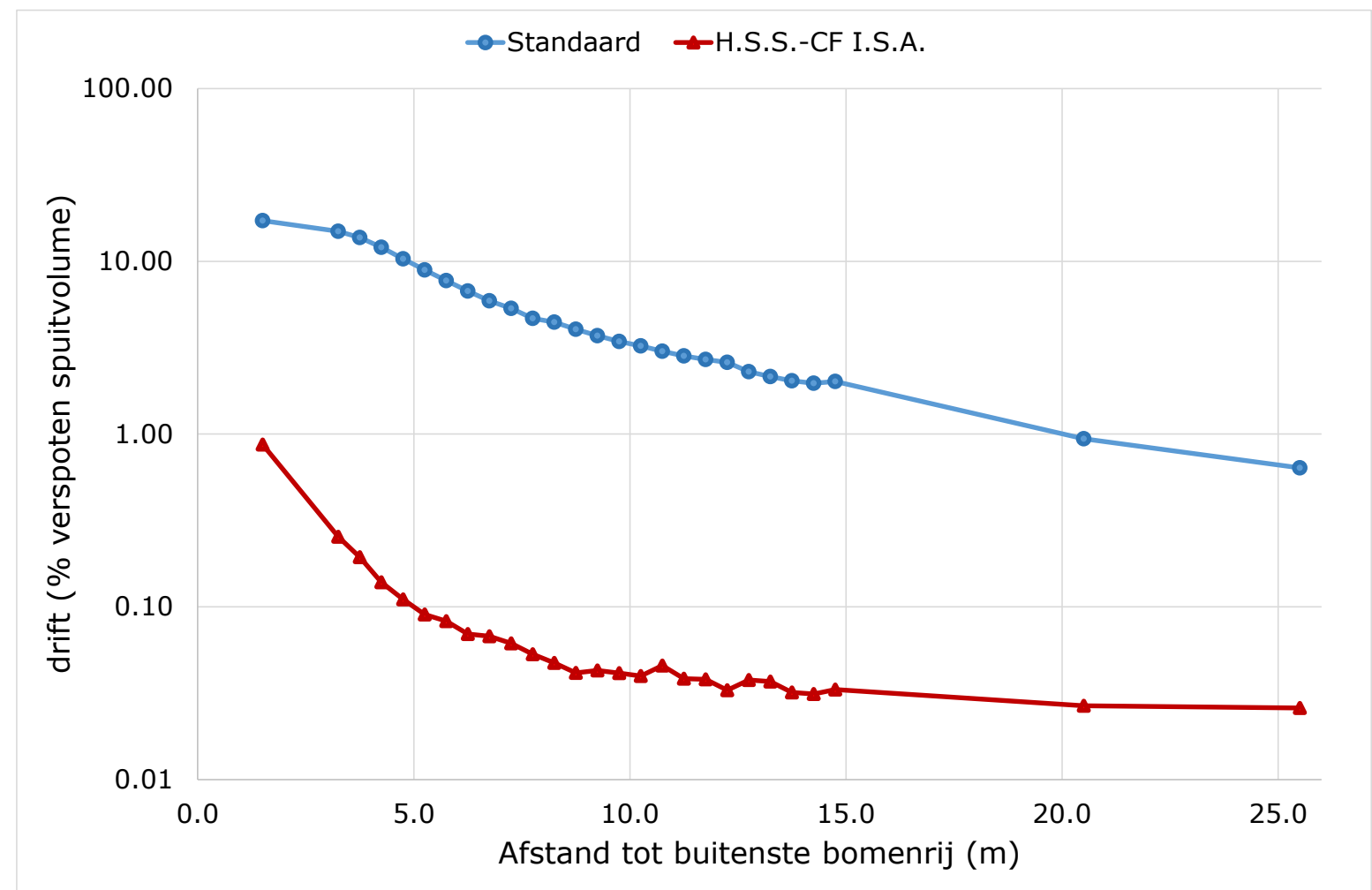

Figuur 3.1 Gemiddelde drift (\% van verspoten hoeveelheid spuitvloeistof per oppervlakte-eenheid) op verschillende afstanden vanaf het hart van de buitenste bomenrij bij bespuitingen van appelbomen in de volblad situatie (BBCH 75-91) met een standaard dwarsstroomspuit (Munckhof met ATR lila werveldoppen) en een H.S.S. CF I.S.A. precisie boomgaardspuit voorzien van Rometron PWM modules op de spuitdophouders, Lechler IDK 90-015 C spuitdoppen en groendetectie sensoren met enkelzijdige bespuiting van de buitenste bomenrij en waarbij het hele perceel op taakkaart werd gespoten.

In Figuur 3.1 en Tabel 3.1 is te zien dat de standaard spuit (Munckhof dwarsstroom met ATR Lila werveldoppen) meer drift geeft dan de H.S.S. CF I.S.A.. In Tabel 3.3 is dat voor de verschillende evaluatiestroken weergegeven. 
Tabel 3.3 Gemiddelde drift (\% van verspoten hoeveelheid spuitvloeistof per oppervlakte-eenheid) op verschillende afstanden vanaf het hart van de buitenste bomenrij bij bespuitingen van appelbomen in de volblad situatie (BBCH 75-91) met een standaard dwarsstroomspuit (Munckhof met ATR lila werveldoppen) en een H.S.S. CF I.S.A. precisie boomgaardspuit voorzien van Rometron PWM met Lechler IDK 90-015 C spuitdoppen en groendetectie sensoren met enkelzijdige bespuiting van de buitenste bomenrij en waarbij het hele perceel op taakkaart werd gespoten.

\begin{tabular}{|c|c|c|c|c|c|c|c|c|c|c|c|c|c|c|c|}
\hline \multirow{3}{*}{$\begin{array}{l}\text { techniek } \\
\text { Standaard }\end{array}$} & \multicolumn{15}{|c|}{ Afstand tot buitenste bomenrij (m) } \\
\hline & \multicolumn{4}{|c|}{$3 \mathrm{~m}$ teeltvrij } & \multicolumn{4}{|c|}{$41 / 2 \mathrm{~m}$ teeltvrij } & \multicolumn{4}{|c|}{$6 \mathrm{~m}$ teeltvrij } & \multicolumn{3}{|c|}{$9 \mathrm{~m}$ teeltvrij } \\
\hline & \multicolumn{2}{|c|}{$3-7$} & \multicolumn{2}{|c|}{$41 / 2-51 / 2$} & \multicolumn{2}{|c|}{$41 / 2-81 / 2$} & \multicolumn{2}{|c|}{$6-7$} & \multicolumn{2}{|c|}{$6-10$} & \multicolumn{2}{|c|}{$71 / 2-81 / 2$} & \multicolumn{2}{|c|}{$9-13$} & $101 / 2-111 / 2$ \\
\hline H.S.S.-CF & 0,13 & $\mathrm{~b}$ & 0,10 & $\mathrm{~b}$ & 0,07 & $\mathrm{~b}$ & 0,07 & $\mathrm{~b}$ & 0,05 & $b$ & 0,05 & $b$ & 0,04 & $\mathrm{~b}$ & 0,04 \\
\hline
\end{tabular}

I.S.A.

Verschillende letters in een kolom duiden op significante verschillen $(a<0,05)$

Op alle stroken geeft de standaard dwarsstroomspuit de hoogste drift. Op de strook 41/2-51/2 m behorende bij een $3 \mathrm{~m}$ teeltvrije zone was dit 9,63\%. De H.S.S.-CF geeft op alle stroken een significant lagere drift. Op 41/2-51/2 m werd met de H.S.S. CF 0,10\% drift gevonden.

\subsection{Drift naar de lucht}

De resultaten van de metingen van de drift naar de lucht naast het perceel zijn weergegeven in Bijlage 4. De gemiddelde drift per spuittechniek tijdens bespuitingen in de volblad situatie (BBCH 7591) staat weergegeven in Figuur 3.2 en in Tabel 3.2

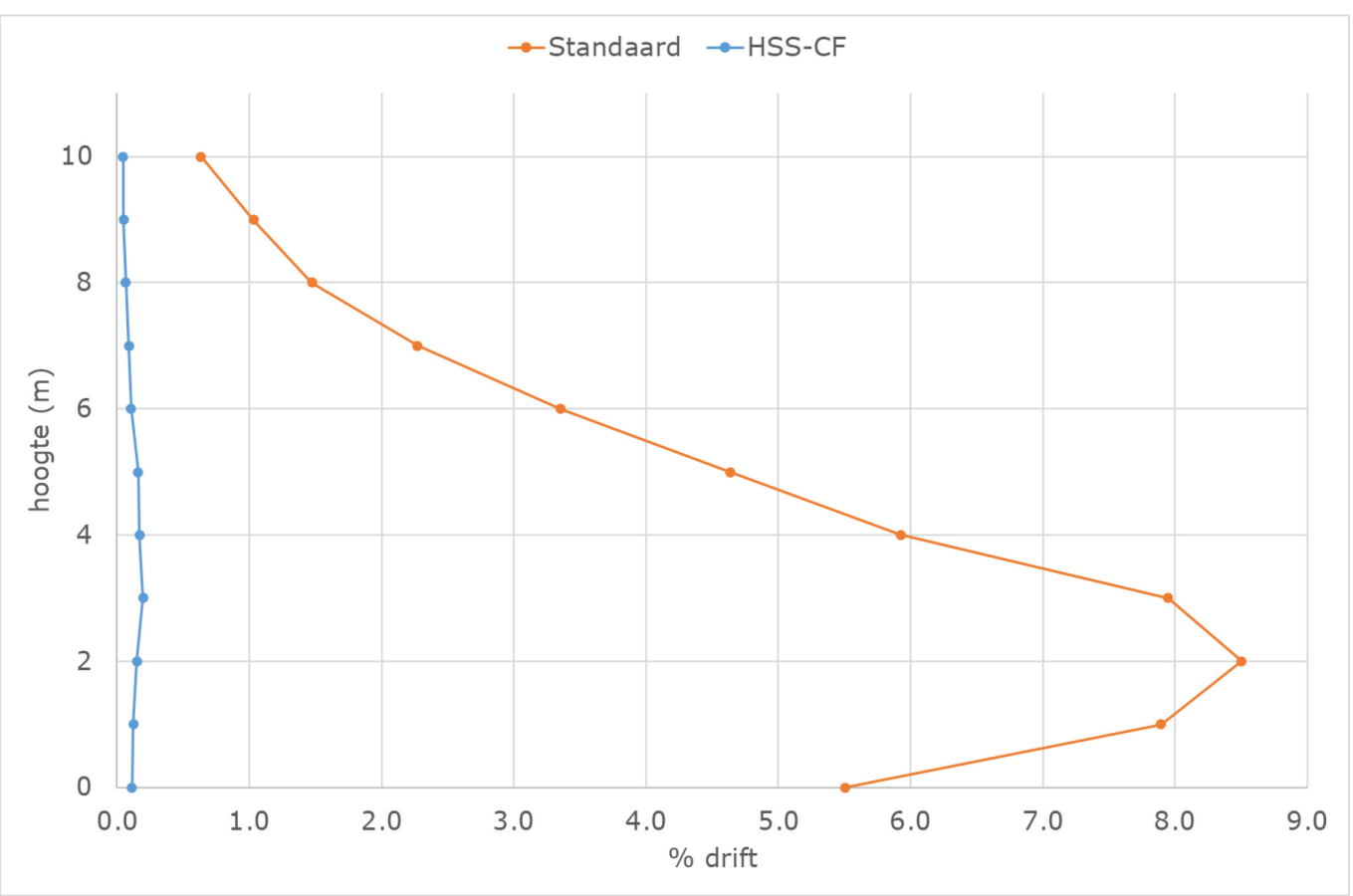

Figuur 3.2 Gemiddelde drift (\% van verspoten hoeveelheid spuitvloeistof per oppervlakte-eenheid) op verschillende hoogtes op $71 / 2 m$ afstand vanaf het hart van de buitenste bomenrij bij bespuitingen van appelbomen in de volblad situatie (BBCH 75-91) met een standaard dwarsstroomspuit (Munckhof met ATR lila werveldoppen) en een H.S.S. CF I.S.A. precisie boomgaardspuit voorzien van Rometron PWM modules op de dophouders met Lechler IDK 90-015 C spuitdoppen en groendetectie sensoren met enkelzijdige bespuiting van de buitenste bomenrij en waarbij het hele perceel op taakkaart werd gespoten. 
In Figuur 3.2 en Tabel 3.2 is te zien dat de standaard dwarsstroomspuit meer drift naar de lucht geeft dan de H.S.S.-CF I.S.A.. De resultaten van de driftmetingen naar de lucht zijn verder uitgewerkt in Tabel 3.4.

Tabel 3.4 Gemiddelde drift (\% van verspoten hoeveelheid spuitvloeistof per oppervlakte-eenheid) op verschillende hoogtes op $71 / 2 \mathrm{~m}$ afstanden vanaf het hart van de buitenste bomenrij bij bespuitingen van appelbomen in de volblad situatie (BBCH 75-91) met een standaard dwarsstroomspuit (Munckhof met ATR lila werveldoppen) en een H.S.S. CF I.S.A. precisie boomgaardspuit voorzien van Rometron PWM modules op de dophouders met Lechler IDK 90-015 C spuitdoppen en groendetectie sensoren met enkelzijdige bespuiting van de buitenste bomenrij en waarbij het hele perceel op taakkaart werd gespoten.

\begin{tabular}{|c|c|c|c|c|c|c|c|c|}
\hline \multirow{2}{*}{$\begin{array}{l}\text { techniek } \\
\text { Standaard }\end{array}$} & \multicolumn{8}{|c|}{$\%$ drift op hoogte $(\mathrm{m})$} \\
\hline & 7,747 & $a$ & 5,856 & a & 1,479 & a & 4,780 & a \\
\hline
\end{tabular}

Verschillende letters in een kolom duiden op significante verschillen $(a<0,05)$

Op alle hoogtes geeft de standaard dwarsstroomspuit de hoogste drift naar de lucht. Gemiddeld over de 0-10 m hoogte was de drift naar de lucht op 7,5 $\mathrm{m}$ van de buitenste bomenrij voor de standaard dwarsstroomspuit 4,780\%. De drift naar de lucht bij de H.S.S. CF I.S.A. op 0-10 m was 0,115\%. 


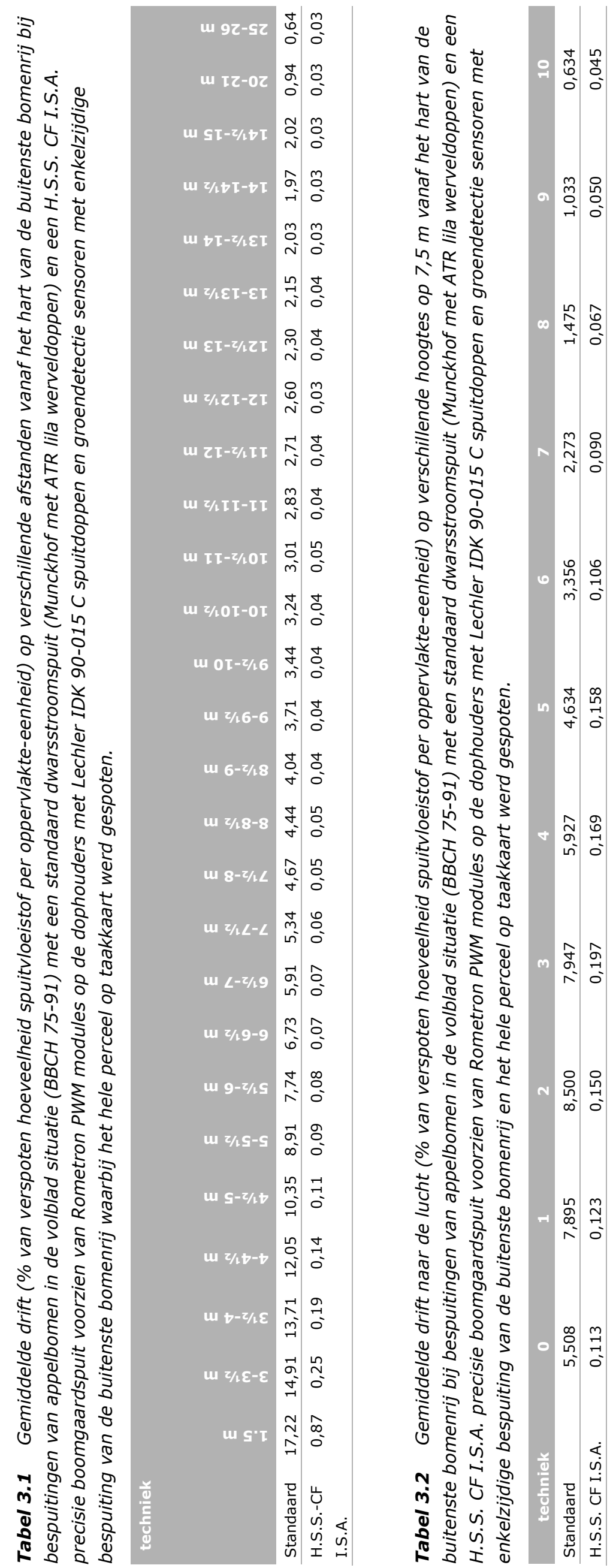




\section{Discussie}

\section{Niet meenemen van bepaalde meetwaarden bij de berekeningen van de driftreductie}

Toen de driftmetingen in 2020 heel andere resultaten gaven dan die in 2019 ontstond bij ons grote zorg. Wij vroegen ons af wat er in 2020 veranderd was wat kon leiden tot de gevonden verschillen. In 2020 zijn de metingen uitgevoerd op de noordelijke helft van het perceel omdat aan de zuidkant van het perceel de bomen gerooid zijn. Op de zuidkant van het perceel is nieuwe aanplant ter vervanging van de oude bomen om over twee jaar daar weer een nieuw meetperceel voor drift te hebben. De boomgaard op de noordkant van het perceel is hetzelfde gebleven. Dit kan dus geen aanleiding zijn voor de gevonden verschillen.

De gebruikte spuit was in 2020 identiek aan die in 2019. Tijdens de uitvoering van de metingen is per gang tussen de bomenrijen gecontroleerd of de begininstellingen juist waren. Tijdens de metingen is de rijsnelheid gemeten, en zijn er geen afwijkingen gevonden. De gespoten druk en het ventilatortoerental is op de manometer en de spuitcomputer geverifieerd. Hier zouden dus geen verschillen opgetreden kunnen hebben. Een echte check op hoe de uitvoering gedaan is kan echter niet uitgevoerd worden. Daarvoor zouden we naast de logbestanden van de spuitdruk en het ventilatortoerental eigenlijk ook een log-bestand van de kritische parameters zoals rijsnelheid, dopafgifte/spuitvolume en dop aan/uit en hoogte sensor signaal moeten hebben gekoppeld aan de positie van de spuit in de boomgaard. In 2020 is een nieuwe fluorimeter in gebruik genomen bij de analyse van de collectoren. Er zijn verschillende checks op de uitkomsten gedaan met metingen met de oude en de nieuwe fluorimeter van dezelfde collectoren met driftdepositie (andere proef) en die waren doorgaans vergelijkbaar. Toch hebben wij het vermoeden dat daar de bron van verschil opgetreden kan zijn bij de analyse van de collectoren van de ene rij collectoren (meetraai) en de andere rij collectoren van dezelfde meting. Het is daarom dat wij de herhalingen waarbij de driftdepositie tussen de meetraaien afweek van het verwachte patroon uit de andere metingen in de rapportage weggelaten hebben. Dit is vooral gedaan om voldoende herhalingen over te houden, zoals volgens het meetprotocol (TCT, 2017) vereist is. Dit lijkt op selectief shoppen in de data, maar dat was niet de bedoeling. Zouden we in plaats van één van de meetraaien de gehele herhaling (beide meetraaien) weglaten uit de analyse van de driftreductie, dus van de herhalingen 6, 9 en 10 allebei de meetraaien niet meenemen, dan komen we ook op een driftreductie van 99,0\%. Maar dan houden we maar 7 herhalingen over.

\section{Driftreductie}

De H.S.S. CF I.S.A. precisie boomgaardspuit voorzien van Rometron PWM modules op de dophouders met Lechler IDK 90-015 C spuitdoppen (75\% driftreductie), lage luchtinstelling (ventilator toerental $1400 \mathrm{rpm}$ ) en groendetectie sensoren waarbij het hele perceel werd gespoten werd bij de drift naar de grond op alle stroken een significante driftreductie gevonden tussen 98,6\%-99,0\% (Tabel 4.1). Bij een teeltvrije zone van $3 \mathrm{~m}$ wordt op de strook 41/2-51/2 m een driftreductie gevonden van 99,0\%

Bij de drift naar de lucht, gemiddeld over 0-10 m hoogte op 7,5 m van de laatste bomenrij, geeft de H.S.S. CF I.S.A. precisie boomgaardspuit voorzien van Rometron PWM modules op de dophouders met Lechler IDK 90-015 C spuitdoppen en groendetectiesensoren waarmee het hele perceel werd gespoten een significante driftreductie van $97,6 \%$. 
Tabel 4.1 Gemiddelde driftreductie (\%) H.S.S. CF I.S.A. precisie boomgaardspuit voorzien van Rometron PWM modules op de dophouders met Lechler IDK 90-015 C spuitdoppen en groendetectie sensoren met enkelzijdige bespuiting van de buitenste bomenrij en het hele perceel werd gespoten ten opzichte van de referentie spuit (Munckhof dwarsstroomspuit voorzien van ATR Lila werveldoppen) op de verschillende evaluatiestroken (overeenkomend met teeltvrije zones van $3 \mathrm{~m}, 41 / 2 \mathrm{~m}, 6 \mathrm{~m}$ en $9 \mathrm{~m}$ ) en naar de lucht (gemiddeld over 0-10 m hoogte) op 7,5 $\mathrm{m}$ van de buitenste bomenrij bij bespuitingen in appelbomen in het volblad stadium (BBCH 75-91)

\begin{tabular}{lccccccccc} 
& \multicolumn{10}{c}{ Driftreductie (\%) op } & & & \\
\cline { 2 - 11 } techniek & $3 \mathrm{~m}$ teeltvrij & $41 / 2 \mathrm{~m}$ teeltvrij & $6 \mathrm{~m}$ teeltvrij & $9 \mathrm{~m}$ teeltvrij & Lucht \\
\cline { 2 - 11 } Standaard & $3-7$ & $41 / 2-51 / 2$ & $41 / 2-81 / 2$ & $6-7$ & $6-10$ & $71 / 2-81 / 2$ & $9-13$ & $101 / 2-111 / 2$ & $0-10 \mathrm{~m}$ \\
\hline H.S.S.-CF I.S.A. & $*$ & $*$ & $*$ & $*$ & $*$ & $*$ & $*$ & $*$ & $*$ \\
\hline
\end{tabular}




\section{$5 \quad$ Conclusie}

Bij driftmetingen tijdens bespuitingen van een appelboomgaard in het volblad stadium (BBCH 75-91) met een H.S.S. CF I.S.A. precisie boomgaardspuit voorzien van PWM modules op de dophouders met Lechler IDK 90-015 C spuitdoppen (75\% driftreductie), lage luchtinstelling (ventilator toerental $1400 \mathrm{rpm}$ ) en bladgroen- en bladmassadetectie sensoren met enkelzijdige bespuiting van de buitenste bomenrij waarbij het hele perceel werd gespoten werd in vergelijking met een referentie boomgaard bespuiting bij een $3 \mathrm{~m}$ teeltvrije zone op de strook 41/2-51/2 $\mathrm{m}$ vanaf de buitenste bomenrij een driftreductie gevonden van $99,0 \%$.

Op grond van dit resultaat kan deze spuittechniek in de driftreducerende techniek (DRT) klasse 99 ingedeeld worden.

Bij de drift naar de lucht, gemiddeld over 0-10 m hoogte op 7,5 m van de laatste bomenrij, geeft de H.S.S. CF I.S.A. precisie boomgaardspuit een driftreductie van $97,6 \%$. 


\section{Literatuur}

Ctgb, 2019. Evaluation Manual for the Authorisation of Plant protection products and Biocides according to Regulation (EC) No 1107/2009 NL part Plant protection products Chapter 6 Fate and behaviour in the environment: behaviour in surface water and sediment version 2.4; March 2019.

EZ, 2013. Gezonde Groei, Duurzame Oogst. Tweede nota duurzame gewasbescherming, periode 2013 tot 2023. Ministerie van Economische Zaken, Den Haag. 2013. 46p.

Huijsmans, J.F.M., H.A.J. Porskamp \& J.C. van de Zande, 1997. Drift(beperking) bij de toediening van gewasbeschermingsmiddelen. Evaluatie van de drift van spuitvloeistof bij bespuitingen in de fruitteelt, de volveldsteelten. en de boomteelt (stand van zaken december 1996). IMAG-DLO Rapport 97-04, IMAG, Wageningen, 38 pp.

I\&M, 2012. Activiteitenbesluit Milieubeheer, Staatsblad 2012 441/643

I\&W, 2017. Regeling van de Staatssecretaris van Infrastructuur en Waterstaat, van 10 november 2017, nr. IENM/BSK-2017/254105, tot wijziging van de Activiteitenregeling in verband met de vermindering van emissies van gewasbeschermingsmiddelen in de glastuinbouw en open teelten. Staatscourant 2017 Nr. 60506

ISO 22866. 2005. Equipment for crop protection - Methods for the field measurement of spray drift. International Standardisation Organisation, Geneva. 2005.

ISO-22369, 2006. Crop protection equipment - Drift classification of spraying equipment. Part 1. Classes. International Standardisation Organisation, Geneva.

LNV, 1998. Wijziging Regeling uitvoering milieutoelatingseisen bestrijdingsmiddelen. Staatscourant 153, 1998.

LNV, 2004. Duurzame gewasbescherming. Gewasbeschermingsbeleid naar 2010. Ministerie van Landbouw, Natuur en Visserij, Den Haag. 2004. 44p.

Michielsen, J.M.G.P., H. Stallinga, D. de Hoog, P. van Dalfsen, M. Wenneker \& J.C. van de Zande, 2019. Spray deposition of a cross-flow fan orchard sprayer with low air and low spray pressure settings. In: J. Cross \& M. Wenneker (eds): Suprofruit2019 - Book of Abstracts. 15th Workshop on Spray Application and Precision Technology in Fruit Growing, July 16-18, 2019, NIAB EMR, East Malling, UK. 2019. p. 47-48

MJPG, 1991. Regeringsbeslissing Meerjarenplan Gewasbescherming 21667, nrs 3-4, 298 pp.

Stallinga, H., J.C. van de Zande, M. Wenneker, J.M.G.P. Michielsen, P. van Velde, N. Joosten, 2011 a. Doppenclassificatie fruitteelt. Driftmetingen van driftreducerende spuitdoppen bij enkelzijdig bespuiten van de buitenste bomenrij in de volblad situatie, Veldmetingen 2008-2009. Wageningen UR Praktijkonderzoek Plant en Omgeving / Plant Research International, PPO/PRI Rapport 366, Wageningen, 2011. 36pp.

Stallinga, H., J.C. van de Zande, M. Wenneker, J.M.G.P. Michielsen, P. van Velde, N. Joosten, 2011 b. Doppenclassificatie fruitteelt. Driftmetingen klassengrensdoppen, Veldmetingen 2008-2009. Wageningen UR Praktijkonderzoek Plant en Omgeving / Plant Research International, PPO/PRI Rapport 365, Wageningen, 2011. 66pp.

Stallinga, H., M. Wenneker, J.C. van de Zande, J.M.G.P. Michielsen, P. van Velde, A.T. Nieuwenhuizen \& L.L.P. Luckerhoff, 2013. Drift en driftreductie van de innovatieve drierijige emissiearme fruitteeltspuit van KWH. WageningenUR Plant Research International, Plant Research International Rapport 458, Wageningen. 2013. 92 p.

Stallinga, H., P. van Velde, J.M.G.P. Michielsen, M. Wenneker \& J.C. van de Zande, 2017. Driftreductie H.S.S. CF boomgaardspuit met blaasmondverstelling en lage luchthoeveelheid. Wageningen UR, Wageningen Research, Rapport WPR-675, Wageningen. 2017. 50 p.

TCT, 2017a. Beoordelingssystematiek emissiereducerende maatregelen open teelt. versie 15 december 2017. [https://www.helpdeskwater.nl/onderwerpen/emissiebeheer/agrarisch/openteelt/driftreducerende/]

TCT, 2017b. Meetprotocol vaststellen driftreductie spuittechnieken [versie 1 juli 2017]. [https://www.helpdeskwater.nl/onderwerpen/emissiebeheer/agrarisch/openteelt/driftreducerende/] 
TCT, 2017c. Meetprotocol vaststellen driftreductie spuitdoppen [versie 1 juli 2017].

[https://www.helpdeskwater.nl/onderwerpen/emissiebeheer/agrarisch/open-

teelt/driftreducerende/]

TCT, 2020a. Lijst met indeling van spuittechnieken in Driftreducerende Techniek-klassen (DRTklassen) (DRT lijst - List with Drift Reducting Techniques).

[https://www.helpdeskwater.nl/onderwerpen/emissiebeheer/agrarisch/openteelt/driftreducerende/]

TCT, 2020b. Lijst met indeling van spuitdoppen in Driftreducerende Dop-klassen (DRD-klassen) (DRDlijst - Drift Reducing Nozzle list).

[https://www.helpdeskwater.nl/onderwerpen/emissiebeheer/agrarisch/openteelt/driftreducerende/]

VSN International, 2019. Genstat for Windows 20th Edition. VSN International, Hemel Hempstead, UK. Wenneker M, Heijne B \& Zande JC van de, 2003. Drift reduction in orchard spraying with a sensorequipped cross-flow sprayer. In: Balsari P, Durochowski G \& Cross JV (eds), Proceedings of the VII Workshop on spray application techniques in fruit growing, June 25-27, Cuneo Italy. University of Turin, DEIAFA, Turin. 2003. 247-256

Wenneker, M., B. Heijne \& J.C. van de Zande, 2004. Invloed venturi-spleetdoppen en luchtondersteuning op emissies bij bespuitingen in de fruitteelt. Praktijkonderzoek Plant \& Omgeving, sector Fruit, PPO-fruit Rapport 2004-03, Randwijk, 2004.

Wenneker, M., Michielsen, J.M.G.P., Heijne, B. \& Zande, JC van de, 2007. Contribution of individual row sprayings to total spray drift deposition next to an apple orchard. In: E. Gil, F. Solanelles, S. Planas, J.R. Rossell \& L. Val (eds). Proceedings of the 8th Workshop on Spray Application Techniques in Fruit Growing, June 2005 Barcelona, Universitat Politècnica de Catalunya, Generalitat de Catalunya, Universitat de Lleida, Barcelona, 2007. p.57-64

Wenneker, M., J.C. van de Zande, H. Stallinga, J.M.G.P. Michielsen, P. van Velde, \& A.T. Nieuwenhuizen, 2014. Emission reduction in orchards by improved spray deposition and increased spray drift reduction of multiple row sprayers. International Advances in Pesticide Application, Aspects of Applied Biology 122, 2014. p. 195-202

Zande, J.C. van de, B. Heijne \& M. Wenneker, 2001. Driftreductie bij bespuitingen in de fruitteelt (stand van zaken december 2001). Instituut voor Milieu- en Agritechniek, IMAG Rapport 2001-19, Wageningen. 36pp.

Zande, J.C. van de, H.J. Holterman \& M. Wenneker, 2007. Doppenclassificatie fruitteelt. Vaststellen referentie spuitdoppen klassengrenzen. Wageningen UR, Plant Research International, WUR-PRI Report 150, Wageningen. 2007. 22 p.

Zande, J.C. van de, M. Wenneker, J.M.G.P. Michielsen, H. Stallinga, P. van Velde \& N. Joosten, 2012. Nozzle classification for drift reduction in orchard spraying. International Advances in Pesticide Application. Aspects of Applied Biology 114. p. 253-260

Zande, J.C. van de, M.C. Butler Ellis, M. Wenneker, P J Walklate \& M. Kennedy, 2014. Spray drift and bystander risk from fruit crop spraying. International Advances in Pesticide Application, Aspects of Applied Biology 122, 2014. p. 177-186

Zande, J.C. van de, M. Wenneker, J.M.G.P. Michielsen, H. Stallinga, P. van Dalfsen, M. Snoussi \& D.C. de Hoog, 2020. Improved spray deposition in full-leaf orchard sprayer type, nozzle type and air setting. International Advances in Pesticide Application, Aspects of Applied Biology 144, 2020. p. $115-122$ 


\section{Bijlage 1 Script statistische analyse}

IRREML

[PRINT $=$ MOD , COM,MEAN, EFF, WALD,DEV;

DISTR = BIN; LINK=LOGIT; DISP $=* ;$

RANDOM $=$ hh*rij; $\backslash$

FIXED = techniek;

$\mathrm{PSE}=\mathrm{ALLD} ; \mathrm{CHECK}=\mathrm{YES}$; meth=fisher] zone; $N B I N=100 ;$

RESID=Rest; FITTED =zoneFIT 


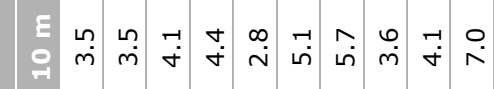

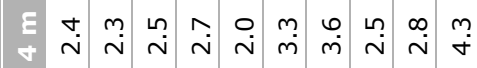

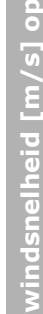

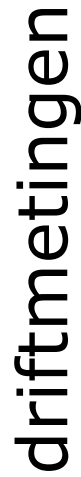

$\frac{1}{0}$

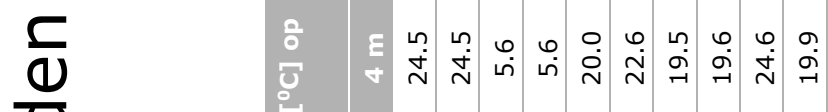

U

$\frac{\varepsilon}{\underline{\sigma}}$

$\frac{0}{0}$

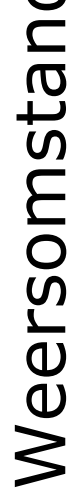

N

(1)

(O)

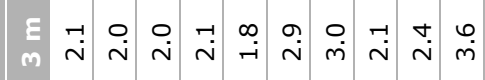

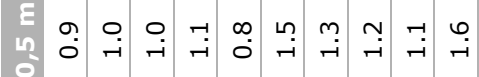

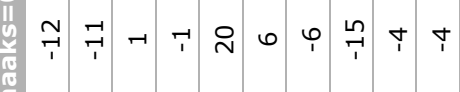

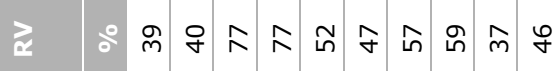

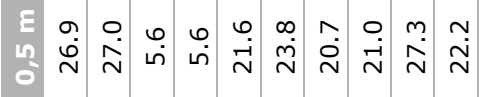

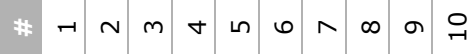

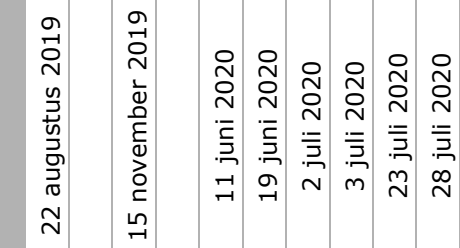

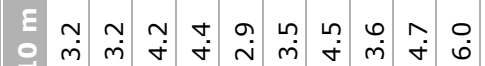

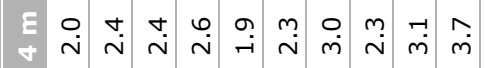

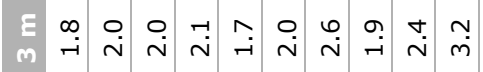

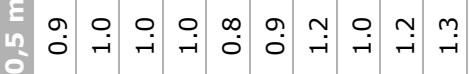

ब

?용

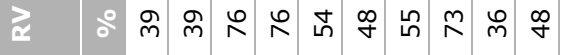

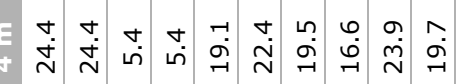

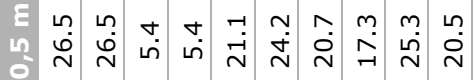

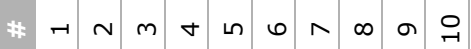

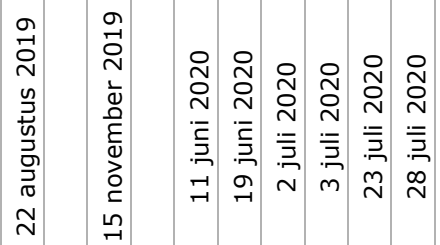




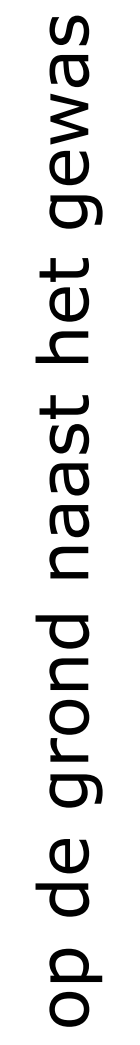

离

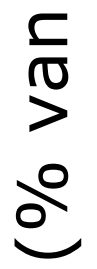

$\frac{0}{0}$
$\frac{0}{0}$
$\frac{0}{0}$
$\frac{0}{0}$
$\frac{0}{5}$

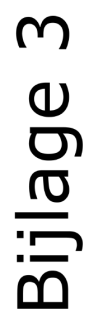

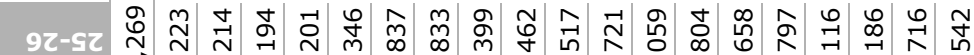

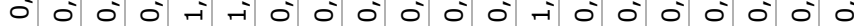

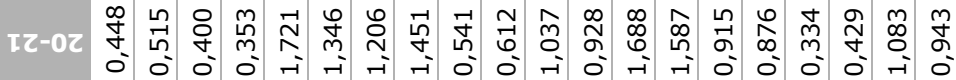

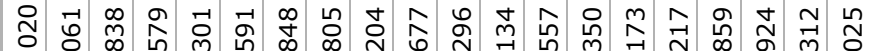

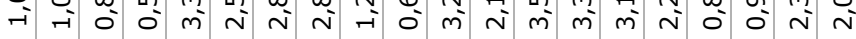
ठ

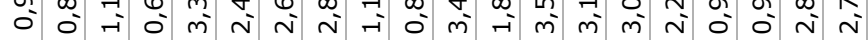
令 $\Rightarrow$ o

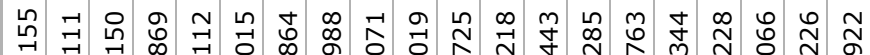
r Fi 吕

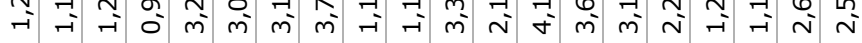
₹ี

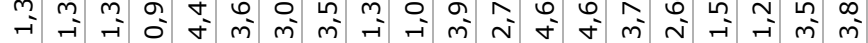
各

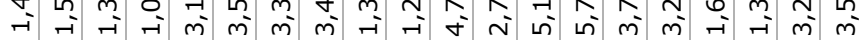

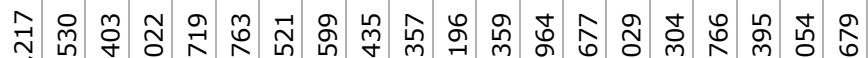
$\rightarrow-i$ -

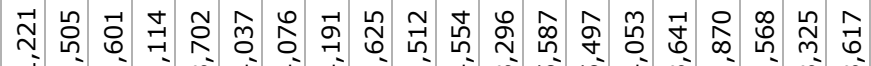

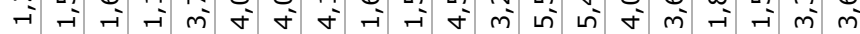

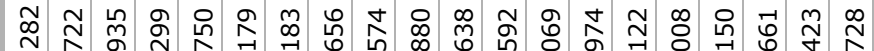

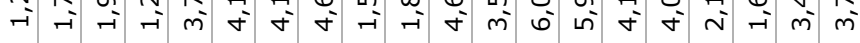

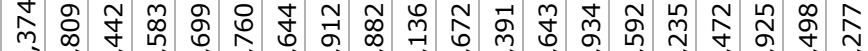

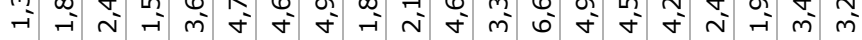

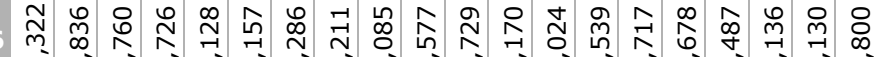

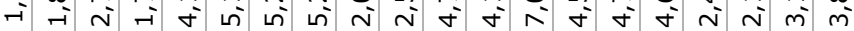

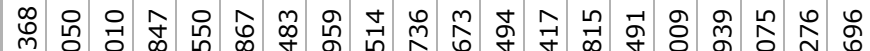

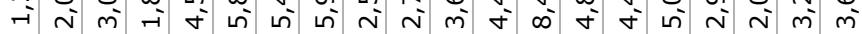

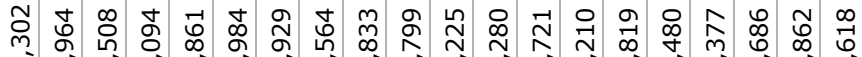

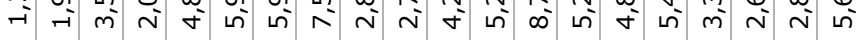

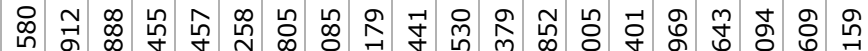

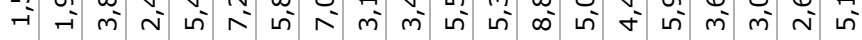
导

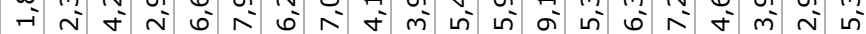

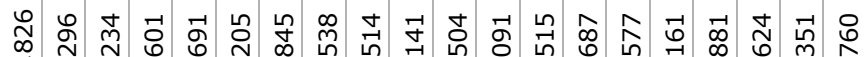

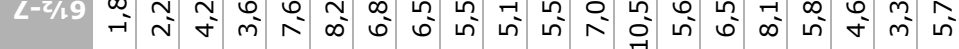

z/19-9

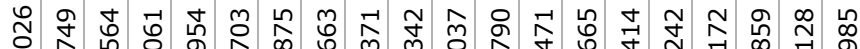

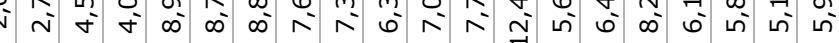

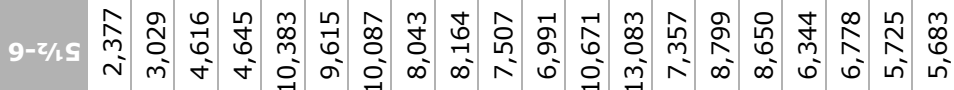

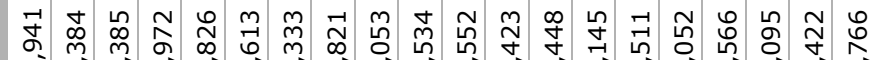
य/s-s n mं कि 苍芯芯芯

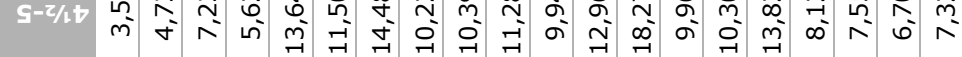

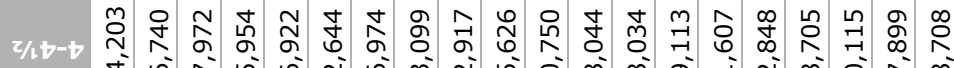
*

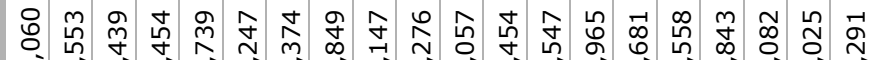

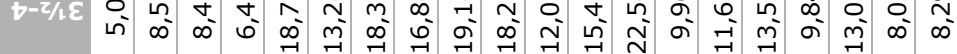
t。

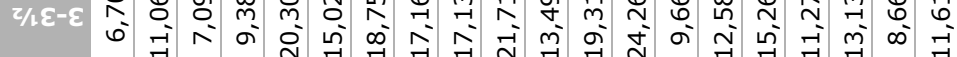

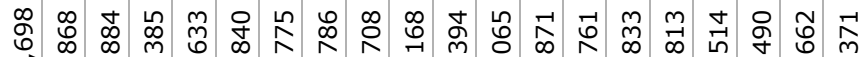

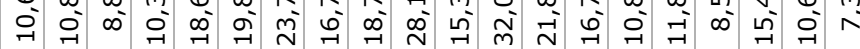

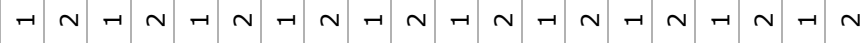
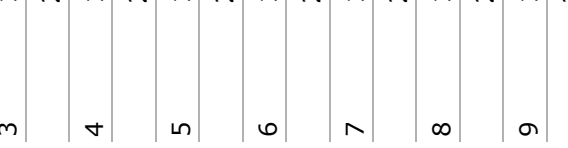


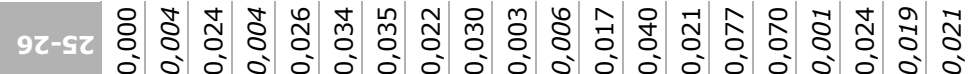
1

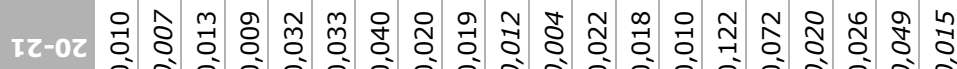

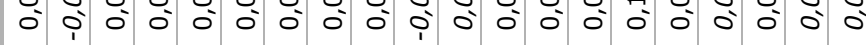
sT-याt

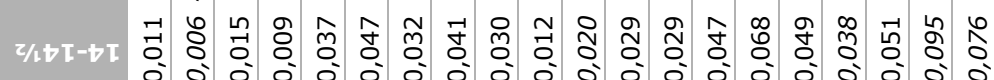

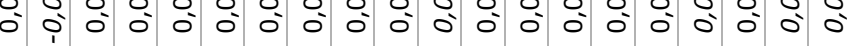

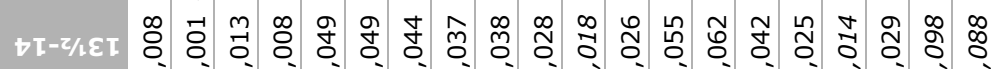

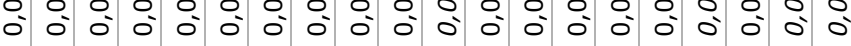

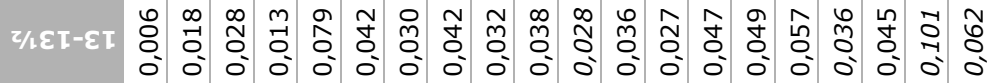

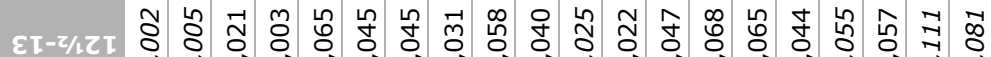

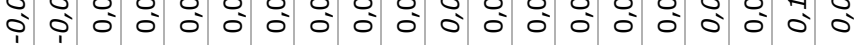

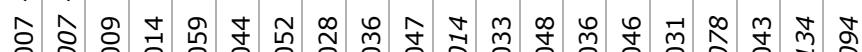

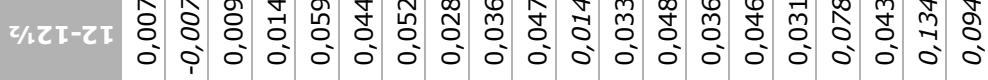

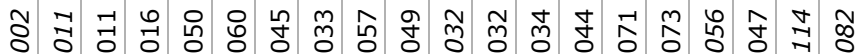

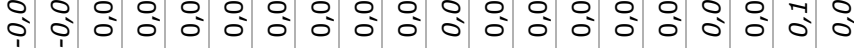

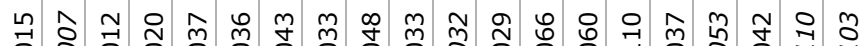

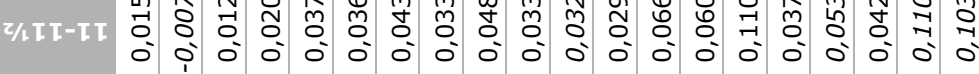

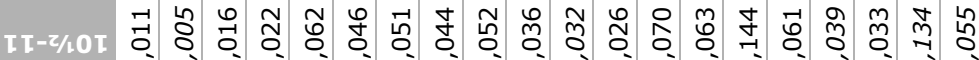

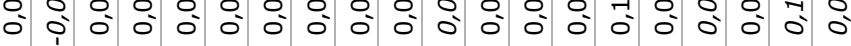

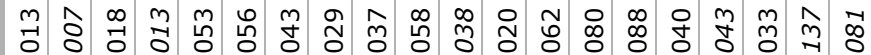

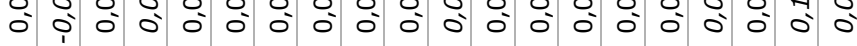

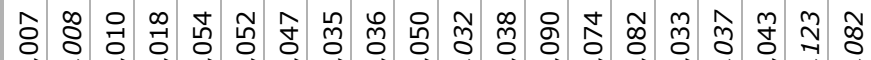

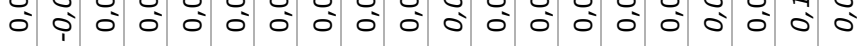

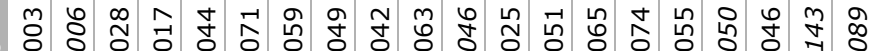

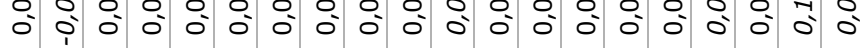

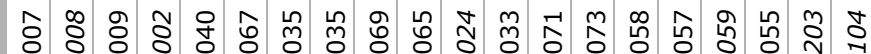

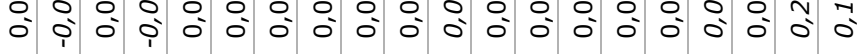

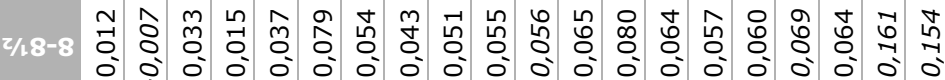

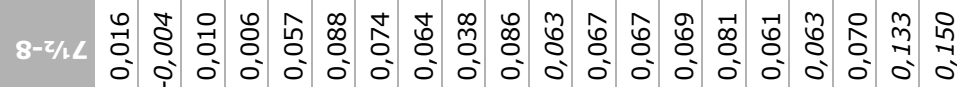

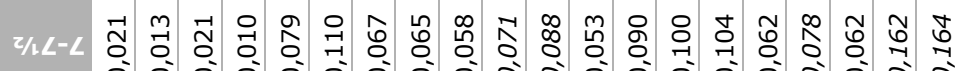

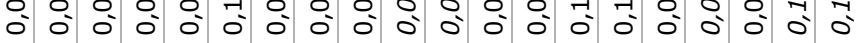

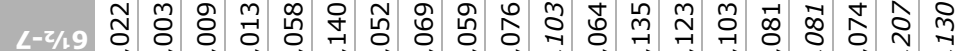

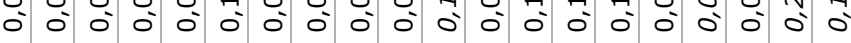

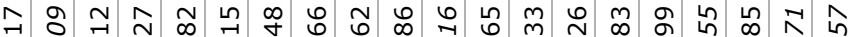

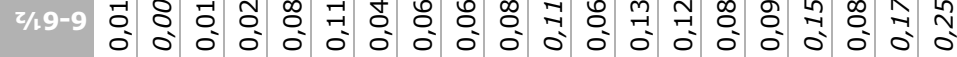
9-z/s च/s-s \&

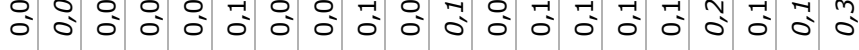

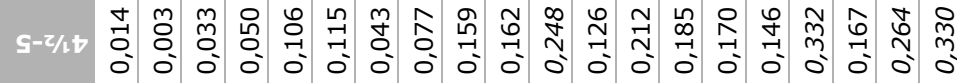

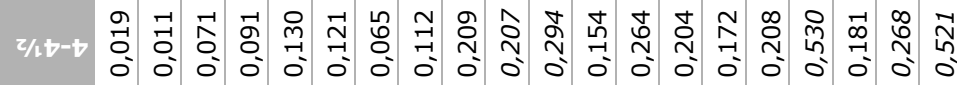

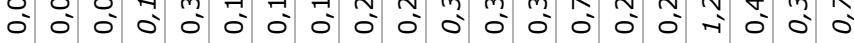

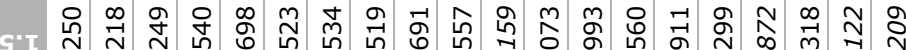

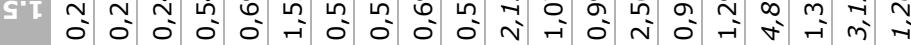

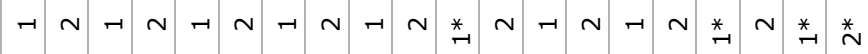




\section{Bijlage 4 Driftdepositie (\% van afgifte) naar de lucht}

Techniek: Standaard dwarsstroom fruitteeltspuit (Munckhof) met ATR Lila spuitdoppen.

\begin{tabular}{|c|c|c|c|c|c|c|c|c|c|c|c|c|}
\hline \multirow[b]{2}{*}{$\#$} & \multirow[b]{2}{*}{ rij } & \multicolumn{11}{|c|}{$\%$ drift op hoogte $(m)$} \\
\hline & & 0 & 1 & 2 & 3 & 4 & 5 & 6 & 7 & 8 & 9 & 10 \\
\hline \multirow[t]{2}{*}{1} & 1 & 3,268 & 6,324 & 5,471 & 6,369 & 4,683 & 5,499 & 2,266 & 2,403 & 1,739 & 1,033 & 0,517 \\
\hline & 2 & 3,254 & 2,693 & 4,463 & 5,072 & 2,534 & 2,925 & 3,513 & 2,169 & 1,862 & 0,646 & 0,302 \\
\hline \multirow[t]{2}{*}{2} & 1 & 3,265 & 4,868 & 3,950 & 3,883 & 3,626 & 2,590 & 1,429 & 1,019 & 0,731 & 0,705 & 0,281 \\
\hline & 2 & 2,290 & 3,423 & 6,147 & 5,996 & 3,468 & 3,124 & 1,486 & 1,246 & 0,850 & 1,161 & 0,519 \\
\hline \multirow[t]{2}{*}{3} & 1 & 5,228 & 9,636 & 9,402 & 6,583 & 5,106 & 4,500 & 3,039 & 2,499 & 1,317 & 0,648 & 0,358 \\
\hline & 2 & 4,284 & 4,950 & 9,104 & 6,501 & 6,554 & 4,264 & 3,622 & 2,030 & 1,095 & 0,525 & 0,514 \\
\hline \multirow[t]{2}{*}{4} & 1 & 4,950 & 9,396 & 13,031 & 13,031 & 10,997 & 7,395 & 5,193 & 2,499 & 1,743 & 1,437 & 0,542 \\
\hline & 2 & 4,592 & 11,246 & 9,462 & 9,880 & 7,823 & 4,701 & 3,531 & 3,263 & 2,188 & 2,064 & 0,899 \\
\hline \multirow[t]{2}{*}{5} & 1 & 2,504 & 3,491 & 4,360 & 5,065 & 3,508 & 1,248 & 3,252 & 1,107 & 0,767 & 0,324 & 0,249 \\
\hline & 2 & 3,718 & 4,759 & 5,263 & 5,320 & 4,282 & 4,340 & 3,271 & 1,790 & 0,775 & 0,315 & 0,155 \\
\hline \multirow[t]{2}{*}{6} & 1 & 6,036 & 7,585 & 7,978 & 1,156 & 1,740 & 2,798 & 2,450 & 4,164 & 0,546 & 0,751 & 0,793 \\
\hline & 2 & 4,477 & 5,640 & 9,890 & 1,113 & 1,455 & 1,750 & 2,653 & 3,898 & 0,666 & 0,699 & 0,583 \\
\hline \multirow[t]{2}{*}{7} & 1 & 8,308 & 12,960 & 12,012 & 12,485 & 8,264 & 4,753 & 3,551 & 2,369 & 2,272 & 1,273 & 1,389 \\
\hline & 2 & 14,854 & 23,334 & 20,076 & 16,446 & 9,507 & 8,113 & 4,335 & 3,534 & 2,031 & 1,957 & 1,177 \\
\hline \multirow[t]{2}{*}{8} & 1 & 11,684 & 10,919 & 8,026 & 13,047 & 8,760 & 7,106 & 4,155 & 2,487 & 3,064 & 1,995 & 1,198 \\
\hline & 2 & 5,023 & 6,247 & 7,852 & 5,766 & 5,715 & 6,330 & 3,943 & 2,260 & 1,332 & 1,318 & 1,027 \\
\hline \multirow[t]{2}{*}{9} & 1 & 8,629 & 6,456 & 8,560 & 8,108 & 5,826 & 4,004 & 3,740 & 2,033 & 0,857 & 0,797 & 0,473 \\
\hline & 2 & 6,432 & 6,437 & 7,498 & 10,593 & 8,543 & 5,507 & 4,454 & 1,800 & 1,168 & 0,426 & 0,433 \\
\hline \multirow[t]{2}{*}{10} & 1 & 4,683 & 7,666 & 9,467 & 11,367 & 11,402 & 8,709 & 4,233 & 4,896 & 3,303 & 1,864 & 0,947 \\
\hline & 2 & 9,343 & 11,788 & 17,997 & 13,693 & 11,797 & 13,083 & 9,946 & 4,117 & 2,694 & 2,084 & 1,118 \\
\hline
\end{tabular}

Techniek: H.S.S.-CF I.S.A..

\begin{tabular}{|c|c|c|c|c|c|c|c|c|c|c|c|c|}
\hline \multirow[b]{2}{*}{$\#$} & \multirow[b]{2}{*}{ rij } & \multicolumn{11}{|c|}{$\%$ drift op hoogte (m) } \\
\hline & & 0 & 1 & 2 & 3 & 4 & 5 & 6 & 7 & 8 & 9 & 10 \\
\hline \multirow[t]{2}{*}{1} & 1 & 0,044 & 0,077 & 0,086 & 0,084 & 0,052 & 0,072 & 0,055 & 0,035 & 0,030 & 0,027 & 0,055 \\
\hline & 2 & 0,061 & 0,089 & 0,096 & 0,112 & 0,086 & 0,065 & 0,047 & 0,049 & 0,062 & 0,045 & 0,102 \\
\hline \multirow[t]{2}{*}{2} & 1 & 0,212 & 0,093 & 0,110 & 0,132 & 0,082 & 0,099 & 0,085 & 0,050 & 0,076 & 0,069 & 0,076 \\
\hline & 2 & 0,117 & 0,083 & 0,066 & 0,116 & 0,068 & 0,067 & 0,065 & 0,066 & 0,063 & 0,078 & 0,082 \\
\hline \multirow[t]{2}{*}{3} & 1 & 0,076 & 0,099 & 0,082 & 0,110 & 0,100 & 0,124 & 0,042 & 0,069 & 0,031 & $-0,003$ & 0,022 \\
\hline & 2 & 0,174 & 0,148 & 0,199 & 0,158 & 0,114 & 0,058 & 0,119 & 0,137 & 0,079 & 0,025 & 0,039 \\
\hline \multirow[t]{2}{*}{4} & 1 & 0,160 & 0,106 & 0,216 & 0,267 & 0,195 & 0,076 & 0,110 & 0,121 & 0,118 & 0,116 & 0,063 \\
\hline & 2 & 0,151 & 0,227 & 0,202 & 0,197 & 0,091 & 0,096 & 0,126 & 0,111 & 0,115 & 0,075 & 0,066 \\
\hline \multirow[t]{2}{*}{5} & 1 & 0,050 & 0,066 & 0,126 & 0,195 & 0,078 & 0,145 & 0,035 & 0,087 & 0,041 & 0,047 & 0,020 \\
\hline & 2 & 0,068 & 0,091 & 0,186 & 0,357 & 0,139 & 0,368 & 0,096 & 0,066 & 0,037 & 0,088 & 0,026 \\
\hline \multirow[t]{2}{*}{6} & 1 & 0,096 & 0,008 & 0,010 & 0,035 & 0,090 & 0,061 & 0,142 & 0,083 & 0,107 & 0,142 & 0,053 \\
\hline & 2 & $-0,004$ & $-0,004$ & 0,003 & 0,021 & 0,022 & 0,056 & 0,052 & 0,084 & 0,039 & 0,031 & 0,053 \\
\hline \multirow[t]{2}{*}{7} & 1 & 0,074 & 0,121 & 0,161 & 0,352 & 0,457 & 0,272 & 0,163 & 0,133 & 0,085 & 0,067 & 0,040 \\
\hline & 2 & 0,194 & 0,212 & 0,208 & 0,405 & 0,321 & 0,314 & 0,188 & 0,115 & 0,044 & 0,026 & 0,001 \\
\hline \multirow[t]{2}{*}{8} & 1 & 0,097 & 0,141 & 0,178 & 0,192 & 0,298 & 0,246 & 0,230 & 0,164 & 0,058 & 0,023 & 0,013 \\
\hline & 2 & 0,250 & 0,161 & 0,150 & 0,124 & 0,258 & 0,213 & 0,125 & 0,088 & 0,073 & 0,053 & 0,039 \\
\hline \multirow[t]{2}{*}{9} & 1 & 0,180 & 0,234 & 0,316 & 0,504 & 0,440 & 0,412 & 0,170 & 0,120 & 0,064 & 0,018 & 0,013 \\
\hline & 2 & 0,086 & 0,254 & 0,326 & 0,332 & 0,340 & 0,265 & 0,160 & 0,066 & 0,117 & 0,027 & 0,020 \\
\hline \multirow[t]{2}{*}{10} & 1 & 0,240 & 0,456 & 0,558 & 0,468 & 0,385 & 0,373 & 0,357 & 0,162 & 0,122 & 0,135 & 0,142 \\
\hline & 2 & 0,279 & 0,325 & 0,441 & 0,450 & 0,636 & 0,343 & 0,302 & 0,342 & 0,107 & 0,129 & 0,079 \\
\hline
\end{tabular}




\section{Bijlage 5 Achtergrond informatie lijst TCT adviezen en driftarme spuitdoppen}

Vermelding van de H.S.S.-CF I.S.A. in de Drift Reducerende Technieken Lijst (DRT-lijst) - TCT:

https://www.helpdeskwater.nl/onderwerpen/emissiebeheer/agrarisch/open-teelt/driftreducerende/

Website van Hol Spraying Systems te Geldermalsen voor meer informatie:

http://www.holsprayingsystems.com/ 
Correspondentie adres voor dit rapport: Postbus 16

6700 AA Wageningen

T 0317480700

www.wur.nl/plant-research

Rapport WPR-1025
De missie van Wageningen University \& Research is 'To explore the potential of nature to improve the quality of life'. Binnen Wageningen University \& Research bundelen Wageningen University en gespecialiseerde onderzoeksinstituten van Stichting Wageningen Research hun krachten om bij te dragen aan de oplossing van belangrijke vragen in het domein van gezonde voeding en leefomgeving. Met ongeveer 30 vestigingen, 6.800 medewerkers ( $6.000 \mathrm{fte}$ ) en 12.900 studenten behoort Wageningen University \& Research wereldwijd tot de aansprekende kennisinstellingen binnen haar domein. De integrale benadering van de vraagstukken en de samenwerking tussen verschillende disciplines vormen het hart van de unieke Wageningen aanpak. 



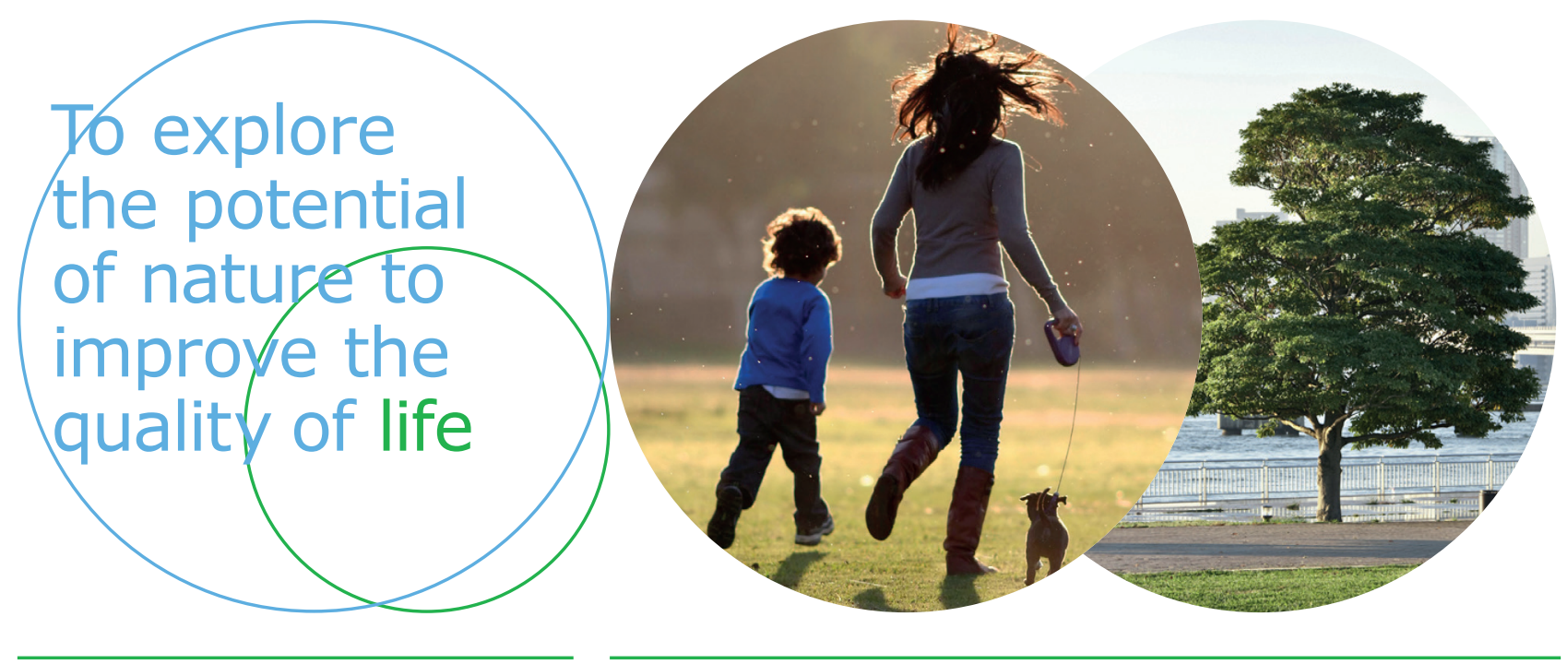

Correspondentie adres voor dit rapport: Postbus 16

6700 AA Wageningen

T 0317480700

www.wur.nl/plant-research

Rapport WPR-1025
De missie van Wageningen University \& Research is 'To explore the potential of nature to improve the quality of life'. Binnen Wageningen University \& Research bundelen Wageningen University en gespecialiseerde onderzoeksinstituten van Stichting Wageningen Research hun krachten om bij te dragen aan de oplossing van belangrijke vragen in het domein van gezonde voeding en leefomgeving. Met ongeveer 30 vestigingen, 6.800 medewerkers ( $6.000 \mathrm{fte}$ ) en 12.900 studenten behoort Wageningen University \& Research wereldwijd tot de aansprekende kennisinstellingen binnen haar domein. De integrale benadering van de vraagstukken en de samenwerking tussen verschillende disciplines vormen het hart van de unieke Wageningen aanpak. 